\title{
LOS HOSPITALARIOS EN LA CORONA DE ARAGÓN Y NAVARRA. PATRIMONIO Y SISTEMA COMENDATICIO (SIGLOS XII Y XIII)
}

\author{
THE HOSPITALLERS IN THE CROWN OF ARAGON AND NAVARRA. PATRIMONY \\ AND TERRITORIAL ORGANIZATION (IN THE XII ${ }^{\text {th }}$-XIII ${ }^{\text {th }}$ AND CENTURIES)
}

\author{
María Bonet Donato \\ Departamento de Historia e Historia del Arte \\ Universidad Rovira i Virgili \\ Julia Pavón Benito \\ Departamento de Historia, $\mathrm{H}^{\mathrm{a}}$ del Arte y Geografía \\ Universidad de Navarra \\ (por orden de firma)
}

Resumen: El estudio de la patrimonialización del Hospital ofrece una imagen de los múltiples espacios que la orden ocupó en el tercio nororiental hispano. Dichas ubicaciones fueron estratégicas con finalidades políticas y sociales, como las situadas en los ámbitos intrapirenaicos, la ruta jacobea, las riberas del Ebro, ciudades, villas, las regiones conquistadas y las fronterizas. Tal pluralidad de espacios coincidió con una variedad de fórmulas de organización comendaticia, siempre sujeta a la jurisdicción o incluso intervención prioral, que respondía en su génesis y contenido a la principal jurisdicción política. Tal estructura patrimonial, territorial e institucional significaba un cambio en la tradición dominial de los regulares y era más acorde a formas políticas como la monárquica, que había alumbrado el gran desarrollo de la orden y la había manejado como un instrumento de su incipiente proyección en el territorio.

Palabras clave: orden del Hospital de San Juan de Jerusalén, encomienda, patrimonio, corona de Aragón y reino de Navarra

Summary: This study of the Hospitallers' patrimony in Northeastern Spain maps the many and diverse spaces which it covered. These places were strategic for political and social purposes and, as such, they were located in the Pyrenees region, on the pilgrimage route to Santiago and the banks of the River Ebro, in cities and villages, and conquered or frontier lands. Such a plurality of properties was matched by a variety of types of commanderies and a flexible structure, which was subject to the jurisdiction of the priory, which added thus having 
a political dimension. This regional, institutional and territorial organization was new in the context of the monastic tradition and more in line with political forms such as the monarchy, which had used the order it as an instrument by which to begin to project its own power across its territories.

Key words: Order of St. John of Jerusalem, preceptory, Crown of Aragon, Kingdom of Navarra

\section{Presentación}

La orden del Hospital de San Juan de Jerusalén tuvo un importante despliegue patrimonial en las tierras del tercio nororiental hispano y fue sustancial comparativamente con el resto de instituciones religiosas, militares o asistenciales en el siglo XII. La implantación territorial de las órdenes militares y su particular organización espacial respondían a las nuevas necesidades de las sociedades hispanocristianas de los siglos XII y XIII. El progreso patrimonial y administrativo del Hospital en la España nororiental refleja, asimismo, la importancia que las instituciones eclesiásticas adquirieron en la nueva configuración del mapa dominical y la aparición de fórmulas de organización más sofisticadas. En este sentido, el entramado de poderes favoreció la consolidación de instituciones como las órdenes militares y la emergencia de estructuras administrativas novedosas jerarquizadas y dinámicas. El estudio de la implantación de los sanjuanistas en los reinos de Navarra, Aragón y en los condados catalanes arroja luz sobre la institución en Occidente y en la Península durante el largo siglo de sus inicios, dado que compartieron características y fórmulas administrativas. Sin embargo, también tuvieron recorridos distintos como consecuencia lógica de la adaptación de la institución a distintos escenarios políticos y sociales. En este sentido, comparar dichas realidades ofrece la posibilidad de comprender mejor la configuración dominical de los hospitalarios y sobre todo las características de una estructura administrativa muy novedosa.

A lo largo de estas páginas, y partiendo de estos planteamientos, nos vamos a detener en el análisis del despliegue y desarrollo del Hospital en el tercio norte peninsular. Para ello se atenderán cuestiones claves vinculadas a la formación patrimonial y del sistema de encomiendas, la gestión de las mismas, la incidencia de otros poderes y finalmente aspectos de las economías de dichas preceptorías. Se tratará, por tanto, de observar los establecimientos sanjuanistas en espacios políticos diferentes o en territorios con escenarios sociales distintos, como eran aquellos con tradición dominical de cuño hispanocristiano y los territorios incorporados en las conquistas. 
La formación patrimonial fue un proceso que empezó en los años treinta del siglo XII, adquirió un impulso destacado y trascendente tras el célebre testamento del rey Alfonso I de Aragón y tuvo continuidad a lo largo de más de un siglo, es decir, hasta mediados del XIII. Dichos desarrollos se acompañaron de la generación de una destacada retícula administrativa, que tenía en la encomienda la circunscripción básica. Una mirada panorámica sobre los espacios donde se estableció la orden de San Juan muestra una variedad significativa, que conformó una territorialización heterogénea de la institución y en definitiva una adaptación a los particularismos locales. Las variantes en la configuración o dinámicas dominicales ofrecían solidez y garantías de éxito a los establecimientos, como pasó en cierto modo con otras instituciones eclesiásticas vanguardistas como el Cister. De esta forma, los sanjuanistas diseñaron una retícula de complementariedad entre los espacios urbanos, los territorios intrapirenaicos, la ruta jacobea, las riberas del Ebro, las tierras interiores de Cataluña y las vastas regiones conquistadas a los musulmanes. Esa articulación patrimonial compleja exigió una organización administrativa acorde, que fueron la cara y la cruz de una institución con novedosas funciones y encajes dentro de los poderes políticos y territoriales desde el siglo XII.

\section{LA FORMACIÓN PATRIMONIAL Y DEL SISTEMA COMENDATICIO}

El patrimonio del Hospital en Cataluña, Aragón y Navarra se formó como resultado de la confluencia de cambios sociales y políticos. La reorganización de la aristocracia feudal, el desarrollo del poder monárquico o condal y la expansión territorial fueron elementos conducentes a la implantación y gran despliegue de la orden. Los cambios en las relaciones de poder, del mapa patrimonial y la ampliación política y territorial cristiana favorecieron las primeras células territoriales o comendaticias. Sin duda, el influjo cruzado, principal en Aragón, y en crecimiento en Cataluña tras el proceso de la unión con dicho reino en las décadas centrales del siglo XII fue un revulsivo para la incorporación de la orden en el programa conquistador y sobre todo en su función de estabilización militar de las fronteras. La obtención del patrimonio en dichos espacios conquistados significó su plena integración y destacada función defensiva en el programa de expansión cristiana.

\section{Los primeros pasos del asentamiento patrimonial}

La aristocracia de implantación territorial en Navarra, Aragón y Cataluña aportó bienes a los hospitalarios desde fechas tempranas, ya en los años veinte 
del siglo XII ${ }^{1}$, y luego la orden alcanzó una posición destacada o principal gracias al testamento del rey de Aragón, Alfonso I. Aquél se entrelazó y condicionó donaciones de los condes de Urgell, Barcelona o incluso de Pallars, así como otros donativos procedentes de la aristocracia feudal en los años treinta o siguientes ${ }^{2}$. En Aragón, en la ribera del río Ebro, o ámbitos próximos, los sanjuanistas obtuvieron propiedades desde mediados de los años treinta en adelante, como en Mallén, Añón, y Remolinos, emplazamientos situados en el área occidental del reino de Aragón, en la zona fronteriza con Navarra, que fueron embriones de futuras encomiendas ${ }^{3}$. Los templarios también alcanzaron bienes en la cinta del Ebro, lo que indica cómo desde temprano ambas órdenes fueron beneficiadas con tierras tanto de interés agrario como de consolidación fronteriza, no sólo frente a los musulmanes sino también ante el vecino territorio navarro, en este caso. Cabe destacar, que templarios y hospitalarios fueron establecidos en las mismas regiones, y por tanto con una pareja funcionalidad.

Las primeras donaciones nobiliarias en Navarra dirigidas al Hospital, empapadas de unas renovadas concepciones y actitudes ante la guerra, y que se datan en la década de los años veinte del siglo XII, fueron seguidas por la intervención monárquica de Alfonso I y más tarde García el Restaurador, dando lugar a un primigenio conglomerado patrimonial en el área intrapirenaica de Uncastillo y Sangüesa, en las orillas del Ebro, así como en la cuenca de Pamplona ${ }^{4}$. Esta retícula dominial, que encajaba con los principales

1.- Joaquim Miret I SAns, Les cases de Templers y Hospitalers en Catalunya, Barcelona, Casa Provincial de la Caritat, 1910, pp. 40-42 y Archivo de la Corona de Aragón o ACA, Gran Priorato de Cataluña o GPC, 2, 120. Lope Garcés, uno de los más estrechos colaboradores de Alfonso I, libró en testamento sus bienes a las tres órdenes (1120-1121), José María LACARRA, "Documentos para el estudio de la reconquista y repoblación del valle del Ebro", Estudios de Edad Media de la Corona de Aragón, 3, (1947-1948), 114.

2.- Donación efectuada de una masía por Ramon Guillem de Berga en 1132 al hospitalario Bermón de Cardona al ingresar en la orden, ACA, GPC, 3, 327. Otros donativos: ACA, GPC, 17, 243 (1138) o 3, 266 (1141). Más dádivas, Ignasi Baiges, Gaspar Feliu, Josep Maria SALraCH, (directores) et alii, Els pergamins de l'Arxiu Comtal de Barcelona, de Ramon Berenguer II a Ramon Berenguer IV, o PACB, Barcelona, Fundació Noguera, 2010, III, 631 (1130); 646 (1131); 749 (1139); las colecciones documentales que no llevan referencia de páginas, se citan por el documento. Para Pallars, Prim BERTRAN I RoIGÉ, “L'orde de l'Hospital al comtat de Pallars (segle XII). Notes i documents", Analecta Sacra Tarraconensia, 53-53, pp. 221-251 y varias fueron las donaciones de bienes de mano del conde de Pallars, como el castillo y villa de Susterris, ACA, GPC, 4, 3 (1152); 13 (1151); 46 (1155); 26 (1162).

3.- Joseph Delaville le Roulx, Cartulaire général de l'Ordre des Hospitaliers de Saint Jean de Jerusalem (1100-1310), París, 1894-1906, I, p. 108; P. DE BofArull (ed.), Codoin, IV, 94 (Remolinos, 1157) y $\mathrm{M}^{\mathrm{a}}$ Luisa Ledesma Rubio, Templarios y hospitalarios en el Reino de Aragón, Zaragoza, Guara editorial, 1982, pp. 127-129.

4.- Santos García Larragueta, El gran priorado de Navarra de la Orden de San Juan de Jerusalén: siglos XII-XIII, Pamplona, Institución Príncipe de Viana, 1957, vol. 1, pp. 85-88; y vol. 2 (la colección documental, que se citará $P S J), P S J$, n. 3, 4, 7, 11 y 15. 
ejes de la articulación espacial del reino, determinaría a la postre una inicial estructura comendaticia, sobre todo por la donación en las proximidades de Pamplona de collazos en Astrain y Cizur (1129 y 1136) - cuya iglesia de San Miguel recibieron también en $1135^{5}$ - y la entrega del palacio e iglesia de Santa María en el burgo nuevo de Sangüesa, con sus diezmos y primicias $(1131)^{6}$.

Misivas del legado pontificio y del Papa protegieron al Hospital en sus primeras intervenciones en tierras peninsulares para obtener limosnas hacia $1113^{7}$. Cabe pensar que desde entonces empezaría su labor en estos territorios y la orden reunió los primeros donativos de bienes muebles, como por ejemplo en Cataluña en los años veinte de dicha centuria. Seguramente, se produjo una pronta iniciativa de mandar recursos a los ámbitos cruzados, al menos teóricamente, concretados en donativos de sumas de dinero, ocasionalmente caballos y armas en décadas sucesivas ${ }^{8}$. A veces las concesiones de bienes muebles u otros con finalidad militar se dirigían a esta orden junto a otra u otras militares, aunque el Temple era la milicia por antonomasia ${ }^{9}$. Todo parece apuntar a que tales bienes favorecerían actividades militares en los escenarios peninsulares y otro tipo de iniciativas como las labores prestamistas. La obtención de recursos fue el embrión de la idea de encomienda y la vinculación a intereses ajenos, distintos o lejanos al emplazamiento donde se estaba produciendo la donación del lugar a la orden, incidiendo en una gestión local poco desarrollada, y sobre todo, nada estable en las primeras décadas. De hecho, no se produjo una primera organización del Hospital en la corona de Aragón hasta mediados del siglo XII y afectó sobre todo a sus

5.- El monarca Alfonso I otorgó a los sanjuanistas un hombre, Garsia Sanz de Azterain; y años después García Ramírez entregó a los sanjuanistas el collazo Gomiz Gomiziz de Cizur Minor cum tota sua radice, en una de las más estratégicas zonas de la cuenca de Pamplona, sobre una de las más extensas y fértiles altiplanicies al sur de la capital, PSJ, n. 7 y 15.

6.- Sangüesa no llegó a prosperar como centro organizador de una encomienda al este del reino. Sería desde el último tercio del siglo XII, cuando villas de carácter rural y próximas al núcleo urbano, como Leache e Iracheta, acabarían vertebrando ese tramo de las tierras del priorato navarro, Julia PAVón, "La relación entre la monarquía y la orden de San Juan de Jerusalén en Navarra (siglos XII-XV). Un primer análisis”, en Julia Pavón y María Bonet (eds.), La Orden del Hospital de San Juan de Jerusalén. Contextos y trayectorias del Priorato de Navarra medieval, Pamplona, CSIC-Eunsa, 2013, pp. 125 y 137.

7.- J. Delaville le Roulx, Cartulaire, I, pp. 12 y 30.

8.- Donación conjunta de doscientos sueldos al Hospital y al Temple en 1134, ACA, 34, 35; de cien sueldos PACB, III, 664 (1133); 677, (1134). Entre los bienes concedidos por Arnau Puig al Hospital en 1156, se mencionaba el caballo y las armas, J. Miret i Sans, Les cases de Templers y Hospitalers, p. 96.

9.- Pere Folc libró sus bienes muebles a las tres órdenes en 1128, PACB, III, 614. Maria Bonet, "Consideracions sobre el patrimoni dels ordes militares a Catalunya en temps de Ramon Berenguer IV", Anuario de Estudios Medievales, 28 (1998), pp. 11-29: p. 23. Otras donaciones de bienes a las tres órdenes en PACB, III, 677 (1134); 749 (1139); 798 (1139); donación de una mula sólo al Hospital, 819 (1143); 829 (1144); ACA, GPC, 28, 2 (1150). 
poderes centrales, aunque aparecieron los embriones o primeras realidades de algunas encomiendas.

Las encomiendas eran las células territoriales de una amplia región o provincia de la orden que se encontraban bajo la autoridad prioral; que en la corona de Aragón terminaría siendo el castellán de Amposta, y en Navarra el prior de Navarra. La estructura y el gobierno de la encomienda estaban sujetos al poder central del priorato y a las obligaciones impuestas por el sistema ultramarino, es decir el Convento central. No se trataba, pues, de una estructura pareja a la cenobítica o de un monasterio, en donde la estabilidad era principal en todos los sentidos, sino que la encomienda se situaba en un sistema orgánico, y por tanto dinámico. El dinamismo afectaba a todo: a la movilidad de personas en los cargos, entre encomiendas, y significativamente a la configuración del sistema comendatario o a la variabilidad de los cargos. De la misma forma era versátil el sistema de relaciones entre los cargos hospitalarios e incluso con las autoridades regionales. Esto explicaría la unión de encomiendas bajo un solo preceptor, la división de alguna de ellas, la reestructuración territorial de otras, la transformación de cargos, como reflejan las modificaciones de la autoridad, nombre e incluso jurisdicción prioral a lo largo del tiempo.

El dinamismo respondía a la concepción misma de la encomienda, que debía contribuir - comandare - a Oriente, y todo lo demás podía ser modificado en beneficio del funcionamiento general o la centralización administrativa. La función militar y los desarrollos fronterizos fueron también factores que afectaron a las dinámicas de cambio de la institución en el mismo corazón de su razón de ser y en sus desarrollos peninsulares. Esta concepción era muy distinta a cierta autarquía que había alumbrado el surgimiento del monacato, y seguía inspirando el benedictismo. Algunas funciones novedosas desplegadas por el Hospital, ajenas a la tradición cenobítica, fueron fomentadas por el monarca, puesto que respondían a sus necesidades políticas.

La formación patrimonial de los hospitalarios en las diversas entidades políticas fue un proceso de larga duración, pero el elemento determinante para su consolidación como una de las principales instituciones eclesiásticas fue el testamento del rey navarroaragonés, Alfonso el Batallador. Como es conocido, el controvertido texto redactado en el sitio de Bayona en 1131, dispuso la transmisión de su potestas soberana a las órdenes del Templo de Jerusalén, del Santo Sepulcro y del Hospital. Con la muerte del Batallador, y tras la negociación formal e inicial con las instituciones beneficiadas, cuyo objeto era liquidar los problemas derivados del anómalo testamento, se emprendió un proceso de compensación y restitución en beneficio de la orden del Hospital, así como del Temple por parte del conde de Barcelona, Ramón Berenguer 
IV y del rey de Navarra, García Ramírez, como ya en su día demostró Martín Duque ${ }^{10}$. Además otros elementos del testamento prefiguraron soluciones posteriores en beneficio de las órdenes, y convirtiéndolas muy claramente en instrumentos políticos del proceso de dilatación territorial hacia el mediodía, y con la función de impulsar la ocupación patrimonial y militar.

La última voluntad de Alfonso I el Batallador anticipó, y en cierta forma conllevó, la instalación y destacado desarrollo patrimonial del Hospital ${ }^{11}$. De hecho, en el mencionado diploma se había reservado un papel destacado de la orden en la ocupación de los espacios a conquistar, concediéndoles Tortosa tras la eventual conquista. Este es uno de los testimonios de predeterminación para las subsiguientes localizaciones territoriales hospitalarias antes de su conquista; aunque, por ejemplo, no se llegaría a ejecutar la donación de Tortosa, salvo en unos pocos bienes testimoniales. La negociación en Aragón a raíz del testamento, llevada a cabo por el conde de Barcelona, Ramón Berenguer IV y el maestre del Hospital en 1140 preludiaba un diseño patrimonial singular y trascendente. La renuncia al reino por parte del Hospital comportó inicialmente la obtención de hombres con sus respectivos patrimonios y prestaciones o censos en Barbastro, Huesca, Zaragoza, Daroca, Calatayud, Jaca, así como in omnibus aliis civitatibus quas Deo iuvante poteris adquirere singulos hominibus... cum domibus et terris et vineis... Constaba, así, que el maestre del Hospital se retenía un hombre de cada "ley" con sus propiedades, en esas ciudades o villas aragonesas que se conquistarían, y en las que había más de treinta moradores ${ }^{12}$.

Resulta difícil adivinar completamente el sentido y alcance de dicha "retención", pero refleja el interés magistral por disponer de dominación en todos los centros de población, y sobre todo o especialmente en los núcleos urbanos. El término retinemus del acuerdo, se acerca en su significación a una eventual idea de retención de dominio, máxime cuando en el diploma se preveía que si el conde no tuviese descendencia legítima, el reino quedaría en manos del Hospital. Tal era la importancia de esta solución — la retención de hombres-, que la orden del Santo Sepulcro reclamó lo mismo a través del representante del patriarca de Jerusalén, que fue el mismo maestre del

10.- Ángel J. Martín DuQue, "La restauración de la monarquía navarra y las Órdenes Militares (11341194)", Anuario de Estudios Medievales, 11 (1981), pp. 59-71. No consta ninguna negociación formal expresa entre el nuevo monarca de Pamplona, García Ramírez, y las autoridades de la orden del Temple o del Hospital; quizá expectantes ante la nueva situación que "teóricamente" imposibilitaba al pamplonés convertirse en intermediario institucional de cualquier posible tipo de convenio o acuerdo.

11.- P. DE Bofarull (ed.), Codoin, IV, 11.

12.- P. De Bofarull (ed.), Codoin, IV, 32. Estas entregas de "hombres", como modelo inicial de presencia dominial de las órdenes en el valle del Ebro, coinciden con los primeros testimonios documentales de devengos en el tramo pamplonés (vid. nota 5). 
Hospital Raimundo, venido de Jerusalén ${ }^{13}$. Esta fórmula, por tanto, implicaba garantías para ambas partes: estabilidad y potencialidad económica para la orden a través de modelos personales de explotación; y también estabilidad política para la monarquía.

Al parecer el maestre aspiraba o consensuó una modesta patrimonialización, aunque ambicionaba tener presencialidad en todos los territorios aragoneses, y específicamente en las principales ciudades. No se trataba, por tanto de alcanzar grandes dominios en esas fechas tempranas, sino más bien asegurar rentas como se desprende de la referencia de la retención de los hombres. Quizá desde el centro de poder oriental, uno de los principales objetivos era alimentar sus necesidades en Tierra Santa, mediatizadas a través de una completa presencia de dependientes de la orden en todo el territorio. La territorialización en el reino era preponderante en relación a una eventual destacada patrimonialización, al menos en esos tiempos iniciales de despliegue. La formación del patrimonio sanjuanista en Aragón, Navarra y Cataluña se caracterizó por reunir muchas células y lugares de sus respectivas geografías, donde las agrupaciones urbanas gozaron de una centralidad destacada. Se podría entender que el acuerdo de 1140 prefiguró la territorialización de la orden en un sentido muy dilatado. A posteriori, se produjeron donativos de personas con su patrimonio por parte del rey y poderes condales, como por ejemplo la donación de un judío y un musulmán en Lérida efectuada en 1170 por Alfonso $\mathrm{II}^{14}$. Seguramente devengos de este tipo podrían enmarcarse en las variadas concreciones de los acuerdos testamentarios. En este sentido, si bien se produjeron algunos donativos de hombres a instituciones monásticas, fueron un tanto distintas.

La solución de Ramón Berenguer IV ${ }^{15}$ para liquidar las posibles aspiraciones de los derechos de los hospitalarios en el reino de Aragón no era nueva. Ya en 1133, el conde de Urgell, Armengol VI, había dispuesto que la orden tuviese un hombre "de los mejores" en cada uno de los castillos ${ }^{16}$. No era una solución idéntica, pero compartía el sentido de territorialización que el Hospital podía adquirir, o se esperaba que desplegase. En este caso, más que

13.- PACB, III, 774.

14.- Ana Isabel Sánchez Casabón, (ed.), Alfonso II. Rey de Aragón, Conde de Barcelona y Marqués de Provenza. Documentos (1162-1196), Zaragoza, 1995, 84: otra donación de un hombre, Pedro Callpena, con su patrimonio, ibidem, 449 (1189). También fue concedido al Hospital, Cicrino con su heredad de Naval a Sigena ut vobis serviant, J. Delaville le RoulX, Cartulaire, I, p. 595 (1193). Pedro II concedió también un judío con todos sus bienes, J. Delaville le Roulx, Cartulaire, II, pp. 50-51 (1205). En sendos casos se trataba de sujetos del rey por su condición.

15.- Antropónimos y topónimos muy asentados en su versión castellana se refieren así, dejándose en catalán aquellos topónimos o antropónimos de proyección local o regional en su uso.

16.- J. Miret i Sans, Les cases de Templers y Hospitalers, p. 24. 
la disponibilidad de rentas o dependencias en localidades, parece que podría tener una finalidad políticomilitar. El conde, quizás, aspiraba a disponer de hombres "fieles" vinculados a la orden, que serían afines a sus intereses en el mosaico de castillos de su territorio, y en un contexto de insuficiente control de su aristocracia.

Una parte destacada de las encomiendas aragonesas se desarrollaron en la fértil ribera o región del valle del Ebro desde estas fechas centrales del siglo XII. Sin embargo, el conde, y luego su hijo, el rey, formalizaron algunas dádivas compensatorias por el testamento en tierras catalanas y de la expansión militar. La donación de Amposta en 1150, de otros bienes menores en Lleida o Tortosa son prueba de ello ${ }^{17}$. La concesión de la décima parte de todo cuanto se conquistase, fechada en 1157, era otro testimonio, quizá el más importante, de la actualización de los acuerdos adquiridos con los hospitalarios inicialmente, y el modo de transferir nuevos beneficios dentro de un contexto algo distinto ${ }^{18}$. Sin duda, la concesión al Temple de la quinta parte de cuanto se conquistase de 1143 sería el antecedente y seguramente el objeto de reclamación del Hospital. Al mismo tiempo su dedicación militar era ya firme y favoreció el interés condal por incorporarlos a las expediciones y ocupaciones de los ámbitos conquistados.

Mientras se operaban estas circunstancias en el ámbito catalanoaragonés, marcadas por el interés mutuo de establecer mecanismos de contraprestación en pro de los intereses y beneficios de uno y otro, entre San Juan y el conde de Barcelona, bajo el paraguas del amplio proyecto de expansión territorial; en Navarra las condiciones y el entorno eran otros. El canal de comunicación del rey para con hospitalarios y templarios fue el de adelantarse para aquietar cualquier posible creación de un foco de conflicto - como de sobra tenía en otros ámbitos-, con puntuales dádivas. Asimismo, los seniores pamploneses - muchos de ellos partícipes de las campañas reconquistadoras con cooperación ultrapirenaica-e imbuidos de la nueva espiritualidad y cercanos a dichas instituciones ${ }^{19}$, serían menores en número y en peso dentro de los círculos de poder que en Aragón, quizá

17.- J. Delaville le Roulx, Cartulaire, I, pp. 141-143; J. Miret i Sans, Les cases de Templers y Hospitalers, pp. 60-65.

18.- P. DE Bofarull (ed.), Codoin, IV, 94.

19.- Las donaciones al Hospital partieron inicialmente de la iniciativa regia, y fueron muy escasas las llevadas a cabo por la nobleza pamplonesa, caso por ejemplo de la donación de iglesia de San Miguel en Cizur Menor, fechada en 1135, y realizada por Lope Íñiguez, PSJ, n. 14, quizá emparentado con el longevo "tenente" del mismo nombre que documenta Antonio Ubieto Arteta en su trabajo recopilatorio, Los "tenentes" en Aragón y Navarra en los siglos XI y XII, Valencia, Anubar, 1973, p. 246. Recuérdese, asimismo, que hasta 1153 son muy pocos los donativos a la orden por parte de los seniores pirenaicos, PSJ, n. 3, 4, 5 y 14. 
por la ausencia de empresas fronterizas y el escaso peso de sus ganancias y patrimonios. De manera que ello habría dado lugar a la creación de un distinto escenario, en Navarra, para el establecimiento de posibles ventajas, beneficios y futuras inversiones.

Las primigenias instancias administrativas sanjuanistas y el signo político de los prioratos

Durante las primeras décadas de los establecimientos hospitalarios, no había una jerarquía territorial desarrollada en el conjunto de dominios. Esto se evidencia en que el maestre del Hospital, venido de Jerusalén, llevó a cabo la negociación por el testamento; aunque su presencia naturalmente respondía a la trascendencia del donativo y en definitiva a la particular organización unitaria de la institución. La centralización sanjuanista y el carácter colegiado de su funcionamiento se reflejaban también en que la solución fue tomada con el convento del Hospital en las partes de Hispania y junto a dos priores. Tal referencia a todos los hospitalarios hispanos unidos en una realidad conventual muestra la modestia de las pretensiones en la estructura administrativa, acorde con una patrimonialización también muy rudimentaria, al menos en 1140. Era tan elemental como para reservarse en Jaca terreno para construir un hospital y una iglesia. Todo apunta a que desde Oriente, la patrimonialización se traducía básicamente en la obtención de recursos, aunque varió muy rápidamente en las décadas posteriores.

En los primeros núcleos patrimoniales surgieron las primeras dignidades hospitalarias, si bien la figura del comendador se asentaría como agente en la segunda mitad del siglo XII y no antes. Previamente, los bailíos se hacían cargo de los bienes, todavía no reunidos en encomiendas o alguna circunscripción parecida, y por tanto la figura del bailío se identificaba con un representante institucional más que con una persona al frente de una comunidad conventual y patrimonial; aunque para realidades futuras se usaría como sinónimo de comendador. Nos podemos fijar en las primeras células de dominios en la Cataluña central. Allí se iban produciendo donativos por parte de señores en los años treinta, que configuraron los orígenes de las futuras encomiendas del Penedès, del Vallés o de Osona ${ }^{20}$. Consta la existencia de un baiulo, de nombre Bremont que regentaba los dominios del Penedès en 1137, cuando compró los derechos de un lugar. En la misma zona, Ramon Guillem de Òdena concedió Pontons a la orden en 1138, que constaba en manos de Ber-

20.- Donación de un honor en el Penedès, ACA, GPC, 17, 244 (1143); J. Miret i SAns, Les cases de Templers y Hospitalers, pp. 68-69 y muchas otras referencias. En otros ámbitos más al norte también: Donación de una masía por parte de Guillermo Ramon de Berga, ACA, GPC, 3, 327 (1132). 
nardo, presbítero y Raimundo Gomball, baiulorum iamdicto ospitalis ipsam terram. Luego en 1141, Bremont, anteriormente referido como bailío, sólo constaba como presbítero en otra donación ${ }^{21}$. En el desarrollo de los cargos del primer núcleo patrimonial en el Penedès se observa la participación de diversos responsables del mismo, sin todavía una vinculación a encomienda o parecido, aunque con la existencia de una serie de cargos menores y por tanto una comunidad incipiente.

A lo largo de las décadas de los treinta y de los cuarenta del siglo XII, primeros años del establecimiento hospitalario, se registró la presencia de bailíos, aunque no se vincularon a ningún ámbito o dominio en su intitulación. En la renuncia de los hospitalarios al testamento del rey aragonés, firma un prior de nombre Martín junto al maestre. Son frecuentes las referencias a los fratres Hospitalis en las donaciones o acuerdos que afectaron al Hospital en la fase inicial de formación patrimonial y con anterioridad a la conformación comendaticia. Con todo, y pese a la aparición de cargos locales o regionales como destinatarios de las donaciones en décadas posteriores, estos acompañaban a la larga locución genérica del nombre de la orden en su referencia a la santa casa del Hospital en Jerusalén o a los pobres de Cristo. Era una fórmula identitaria que acompañaba al nombre del dignatario regional, y evidenciaba que no se perdía la referencia del sentido internacional y jerosolimitano de la orden. Incluso la donación tenía sólo como destinatario al Hospital o a los señores del Hospital ${ }^{22}$.

Al tiempo que se procedía a esta implantación patrimonial, la institución iba diseñando su organización provincial y jurisdicción administrativa. Durante la primera mitad del siglo XII, los ámbitos patrimoniales en los reinos de Aragón y Pamplona y condados catalanes, tenían como autoridad de referencia occidental al Priorato de Saint Gilles, que refleja, la existencia de una centralización institucional desde sus comienzos ${ }^{23}$. Había, pues, un poder central de la orden, destinado a supervisar o gobernar el proceso de despliegue en el tercio norte peninsular vinculado a Saint Gilles en Francia meridional; así, para algunos autores la región dependía del priorato de Saint Gilles. En este plano, cabe comprender la referencia al cargo de prior del Hospital en

21.- J. Miret i SAns, Les cases de Templers y Hospitalers, pp. 33 y 34.

22.- Por ejemplo en la resolución de un pleito en la curia de conde Ramón Berenguer IV en 1151, que afectaba a los hospitalarios, sólo se les menciona genéricamente como freires del Hospital de Jerusalén, PACB, III, 936 y otros ejemplos, entre muchos, PACB, III, 803; 819; 820; 826; 837; 881; 931, 936 (entre 1142 y 1151 ).

23.- Arnaldo, al que S. García Larragueta identifica con el prior de Saint Gilles, recibe la donación de la iglesia de San Miguel de Cizur Menor en 1135: Facta karta XIIII kalendas decembris, in era $M^{a}$ $C^{a}{ }^{L X X}{ }^{a}$ III $^{a}$ in manu fratrum Hospitalis Iherusalem Martinus et Arnaldus presbiteri, PSJ, n. 14. 
toda Hispania del $1144^{24}$. El mismo prior de Saint Gilles se denominaba atque Ispanie en $1153^{25}$. Donativos importantes se dirigían incluso al maestre Raimundo, aunque acompañado del prior de Saint Gilles, como sucedió con la donación de Amposta de 115026. El conde de Barcelona reconoció una deuda contraída con el Hospital directamente al maestre Raimundo en $1158^{27}$.

Con posterioridad, en los años cincuenta, aparecieron las autoridades priorales propiamente peninsulares, aunque inicialmente para el tercio norte cabría apuntarse una lógica filiación provenzal. Una primera referencia a la mencionada atribución en el oriente hispano fue la de prior de Aragón y de Barcelona, magister en Aragone et in Barchinone, en este caso Guillermo de Belmes. Se trataba del documento en el que junto a Pedro de Rovera, con el mismo título pero para el Temple, se consignaban por acuerdo de permuta Mallén para el Hospital y Novillas para el Temple en 114928; convenio alcanzado por ambos en el asedio de Tortosa, y en compañía de otros miembros del Temple y el Hospital. Dicha denominación refleja cómo desde temprano hubo una intencionalidad de generar demarcaciones priorales adecuadas a las realidades políticas. Sin embargo, este cargo no tuvo continuidad en su uso en el Hospital, y además llama la atención que coincidiera con el del Temple en ese momento, confirmando cierta situación coyuntural. Guillermo de Belmes consta en una ocasión como prior de Aragón en una donación en Grisén, que fechamos con mucha seguridad en 1154 y no $1144^{29}$.

La siguiente fórmula conocida fue la del prior de Navarra y Aragón, cargo que recayó también en Guillermo de Belmes desde 1154, quien junto con su sucesor Miró recibieron beneficios del rey de Navarra ${ }^{30}$. De hecho, su presencia en la documentación de la soberanía pamplonesa fue significativa en relación a su presencia en la documentación en otros ámbitos ${ }^{31}$. Eso no

24.- Ma Luisa Ledesma Rubio, La encomienda de Zaragoza de la orden de San Juan de Jerusalén en los siglos XII y XIII, Zaragoza, Cátedra, 1967, pp. 35 y 507.

25.- J. Delaville le RoulX, Cartulaire, I, p. 169 y p. 200.

26.- También recibió una donación de Gerona en 1148, J. Delaville le Roulx, Cartulaire, I, 178 y 181 (Amposta ya citado).

27.- J. Delaville le RoulX, Cartulaire, I, p. 200.

28.- De Albon, marqués, Cartulaire Général de l'ordre du Temple (1119?-1150), París, Libraire Ancienne, Honoré Champion éditeur, 1913, 553 p. 339. Dicho acuerdo se cita en ACA, GPC, 13, 139.

29.- Pensamos que el documento ofrece un error de datación o copia ya que la fecha de 1182 por la era corresponde a 1144, pero indica expresamente in anno capta fuit Sibrana que se ha establecido en 1154 o 1153, y además concuerda con otras referencias de cargos hospitalarios. La fecha de 1144 era muy temprana para la existencia del prior de Aragón, Archivo Histórico Nacional o AHN, Cartulario Magno, III, o códice 650, f. 310. M ${ }^{\mathrm{a}}$ L. Ledesma Rubio, La encomienda de Zaragoza, p. 35 toma como válida la fecha de 1144 .

30.- Sobre la figura de Guillermo de Belmes y el origen de las primeras demarcaciones priorales en Navarra y Aragón, véase S. GARcía LARRAGUETA, El gran priorado de Navarra, pp. 48-58 y 62-69.

31.- PSJ, n. 20, 22, 23, 24, 25, 29. 
fue óbice para que dicho cargo obtuviese bienes en Zaragoza u otros lugares de Aragón, de manos de particulares. Así Miró fue beneficiado con bienes en Zaragoza en 1165, y constaba como qui erat prior de Saragosa et de Navarra, favorecido también en la misma ciudad por Renal de Tuleda, y denominado del mismo modo. Como indica $\mathrm{M}^{\mathrm{a}} \mathrm{L}$. Ledesma, esta relación con Zaragoza podría responder a que el regnum caesaraugustanum se mantuvo en la "conciencia de la época" 32 . Sin embargo, no parece tan claro que esa circunscripción o cargo abrazasen los dominios hospitalarios de Aragón y Navarra de una manera inequívoca, como veremos.

La aparición y función de una realidad prioral respondió a la consolidación de la entidad política en la que se desarrollaba la orden, que finalmente explica el mapa de los prioratos hispanos. En este sentido, vale la pena llamar la atención sobre el prior de Navarra y Aragón, que no figuraba como beneficiario del conde de Barcelona o su hijo el rey de Aragón, quienes optaron por el maestre o prior de Amposta, como se denominó en las primeras décadas de su recorrido ${ }^{33}$. Seguramente la referencia a Amposta facilitaba la vinculación a la compleja unidad política surgida de la unión y tenía un ejemplo cercano en el priorato de Saint Gilles, que también aludía a la localización de la sede institucional en vez de la región. En 1154 se documenta el maestre de Amposta, quien figuraba como magister de Emposte et de villam Sancti Celedoni, es decir concretando su jurisdicción al sitio donde recibió la donación $^{34}$. Este particular cargo, que combinaba la realidad prioral y la vinculación territorial refleja el dinamismo de oficios y nomenclaturas en décadas iniciales. En este sentido, el maestre se llamó también prior de Amposta, y terminó siendo el castellán de Amposta décadas más tarde, ya en el siglo XIII. La comunidad de Amposta era ya una realidad entre 1155-1157 con freires, clérigos, y conversos, al frente de la misma estaba P. Humberto, "ministro" o prior -1155-1156 - y Gaufredo de Bresil en 115735. Para ese año había ya un comendador de Amposta, Pedro Autendo y un capellán del maestre ${ }^{36}$.

32.- Ma L. Ledesma Rubio, La encomienda de Zaragoza, pp. 40 y 41 respectivamente. La donación de Aliaga de 1163 efectuada por Sancho de Tarazona recayó también en el prior de Aragón y Navarra, León Esteban Mateo, Cartulario de la encomienda de Aliaga, Zaragoza, 1979, 2.

33.- Diversas donaciones del conde o el rey tenían como destinatario el maestre de Amposta, como por ejemplo las de Caspe (1181-1182); Olocau (1180); Ulldecona (1180), Cabañas y Alpartir (1180) J. Delaville le RoulX, Cartulaire, I, pp. 407, 399, 398, 398-9 o la donación de Codony, efectuada por Sancha en 1189, ibídem, 1187.

34.- J. Miret I Sans, Les cases de Templers y Hospitalers, 96.

35.- En documentación referente a una disputa con el obispo de Tortosa se documenta el mencionado prior y otros, Antoni VirgiLI, (ed.): Diplomatari de la catedral de Tortosa (1062-1193), Barcelona, Fundació Noguera, 1997, 51, 70, 71.

36.- J. Delaville le Roulx, Cartulaire, I, p. 195 y Jesús Alturo i Perucho, Diplomatari d'Alguaire $i$ del seu monestir santjoanista de 1076 a 1244, Barcelona, Fundació Noguera, Barcelona, 1999, 8. 
Una trascendente donación de Ramon Berenguer IV, del mismo año de 1157, se destinó al maestre del convento, Raimundo y se precisó que se ponía en sus manos y en las de Guillermo de Belmes, aunque no indicaba su cargo, por entonces prior de Navarra, Reinardo de Laurada y Gaufredo de Bresil, de quien se indicaba que era el prior de Amposta con su capellán ${ }^{37}$. Concedió varios bienes y la décima parte de las tierras que se conquistarían ya referida. En esta oportunidad, como en tantas otras, había una presencia colegiada de los distintos niveles de la jerarquía, pero curiosa y significativamente el documento obviaba el cargo de Guillermo de Belmes, aunque estaba presente y aparecía justo después del maestre conventual.

Pese a la aparición de la potestad prioral en Aragón y Cataluña, algunos diplomas del rey Alfonso "el Casto" se dirigieron al prior de Saint Gilles en el ámbito de la corona de Aragón, o en algún otro caso al prior del Hospital en Citramar en décadas sucesivas ${ }^{38}$. El prior de Saint Gilles continuó siendo beneficiario de documentos emitidos por las autoridades políticas relativos a temas patrimoniales, aunque a menudo figuraba en compañía de la dignidad provincial, como en los del rey Alfonso II destinados a la fijación del mapa patrimonial de los hospitalarios. Su intervención se produjo incluso cuando se trataba de discusiones o soluciones con el Temple u otros señoríos. Dichas actuaciones radicaban en el hecho de que su padre y él mismo habían sido agentes de la gran formación patrimonial. Esta situación fue fundamental a la hora de legitimar las trascendentes intervenciones que la monarquía llevaría a cabo en el patrimonio sanjuanista cuando respondió a sus necesidades o intereses.

En ambos casos, se trataba de donaciones importantes que seguramente derivaban de la liquidación del testamento en un sentido estricto o de la consolidación de los vínculos con la orden en un sentido más amplio, aunque en relación al compromiso adquirido con la autoridad sanjuanista. La dirección de las donaciones a un cargo o a otro surgía de la jerarquía de la institución y no de una cierta indeterminación en la jurisdicción de los cargos. El rey de

37.- P. De Bofarull (ed.), Codoin, IV, 94.

38.- J. Delaville le Roulx, Cartulaire, I, p. 295: donación del rey Alfonso de la Rápita a favor de Guido de Mahun, prefati Hospitalis citra mare preceptoris en 1171. Otras concesiones regias como la de Ulldecona de 1178 se destinaron al prior de Saint Gilles, en ese caso beneficiado junto al maestre de Amposta, ibidem, p. 368 y una donación del rey en manos del prior de Saint Gilles de 1182, ibidem, pp. 420-1. Algunas permutas o convenios con el Temple bajo la autoridad regia referían al prior de Saint Gilles como representante de la orden, A. I. SÁnchez CASABón, (ed.), Alfonso II, 431 (1186), en este caso junto al maestre de Amposta; 495 (convenio Temple-Hospital de 1189) y en alguna permuta contemporánea, el rey se refirió sólo el maestre de Amposta, ibídem, 340 (1182). También se dirigió a Armengol de Aspa la donación de Canals, era entonces prior de Saint Gilles, pero antes había sido maestre de Amposta, J. Delaville le RoulX, Cartulaire, I, pp. 420-421. 
Aragón sabía a quién destinaba sus donaciones y por qué. Estaba interesado en favorecer una unidad jurisdiccional propia y, a su vez, comprometido con la institución en un sentido más amplio a partir de las premisas del testamento. En otro orden de cosas, pero dentro de las mismas dinámicas de cierta autoridad por parte del prior de Saint Gilles en los prioratos hispanos orientales, este siguió interviniendo en asuntos de importancia y trascendencia para la orden hasta finales de los años ochenta del siglo XII ${ }^{39}$. También hubo situaciones de gran relieve para la institución, como la confirmación de la regla de Sigena en 1188, que contaron con la presencia de cargos de otros prioratos ${ }^{40}$. La participación de cargos generales que abrazaban diversos prioratos o de Hispania, en asuntos regionales o locales tuvo continuidad en los siglos siguientes ${ }^{41}$, y respondía a la misma idea unitaria fundacional que jamás perdió la institución, pese a la progresiva configuración estable de prioratos o encomiendas, claramente en el siglo XIII.

Sobre el priorato de Navarra cabe apuntar a los años finales de la década de los sesenta y principios de los setenta como el momento en el que se fraguaron las circunstancias para formar una circunscripción coincidente con las fronteras del reino, en ese momento bajo el gobierno de Sancho el Sabio. El mes de febrero del año 1173, este monarca puso bajo su vinculación directa a omnibus fratribus sancti Hospitalis Iherusalem in regno meo habitantibus, hecho que desprende ciertamente una estructura independiente de la provincia navarra con respecto a la aragonesa, aunque la ausencia de la mención del cargo y persona titular del priorato en todo el texto permita afirmarlo tajantemente. Un pergamino datado el año anterior, 1172, desvela el nombre de esa probable primera autoridad sanjuanista en Navarra: García Ramírez, quien poco después sería objeto de un importante donativo por parte del obispo de Pamplona. El 30 de junio de 1173 el obispo Pedro de Pamplona concedió con su capítulo a los sanjuanistas la casa de la cofradía de Barañáin, en los terrenos que demarcan hoy aproximadamente el barrio de San Juan de Pamplona, significándose como el apoyo de la cátedra epis-

39.- Agustín Ubieto Arteta, Documentos de Sigena, Valencia, Anubar, 1972, 5 (1187) y J. Alturo I PERUCHO, Diplomatari d'Alguaire, 55 (1186).

40.- A. Ubieto Arteta, Documentos de Sigena, 8.

41.- El gran comendador del Hospital, Aimerico de Paz, intervino junto al capítulo de la castellanía de Amposta en la concesión de las costumbres de Aliaga, J. Delaville Le Roulx, Cartulaire, II, p. 193. Aurembiax de Urgell confirmó a la orden todas las donaciones que se habían hecho desde el condado de Urgell en manos de Pedro Ferrandiz, preceptor quinque regnorum in Spanie en 1230 , J. Alturo i Perucho, Diplomatari d'Alguaire, 281. Tambien fue referido como Petro Ferrandis in cismarinis partibus maximo preceptori et aliis magistris et fratribus. El "comendador general de los cinco reinos de Hispania" intervino a lo largo del siglo XIII, J. Delaville le RoulX, Cartulaire, II, p. 961 (1250) y también se llamó gran comendador de Hispania, J. Delaville le Roulx, Cartulaire, III, p. 229 (1270). 
copal a dicho proyecto. Resulta llamativo que la donación iba precedida por la supplicatione venerabilium fratrum videlicet Petri de Areis, magistri in Yspanie [et Gar]sie Remiri sub eo prioris in Nauarra et in Aragone. Es posible, a la luz de estos indicios, que finalmente fuera en estos años, cuando se erigiera la región prioral vinculada al reino de Navarra. Aun con todo, quedarían pendientes algunos razonados retoques para hacer coincidir la geografía del rectorado del Hospital con la monárquica. En este sentido, el priorato de Navarra, como otros prioratos peninsulares, fueron expresiones de las nuevas realidades políticas, y fruto de una clara, e interesada, vinculación a las monarquías emergentes ${ }^{42}$.

La autoridad sanjuanista en el tercio oriental hispano se fue ajustando al mapa político, si bien esas fórmulas regionales acordes a la formación política, no siempre fueron las referenciales sino otras como los cargos relativos a Hispania, el prior de Saint Gilles o el mismo maestre. De forma paralela se configuraron las encomiendas a lo largo de décadas. En este sentido, cabe diferenciar los procesos de patrimonialización de aquellos de formulación institucional, aunque a veces una situación podía incidir en la siguiente. En todo caso, los procesos de formación comendaticia fueron variados, respondiendo a las circunstancias locales y fruto sobre todo de la flexibilidad en el diseño institucional.

\section{La consolidación territorial y la definición del sistema comendaticio}

Algunas encomiendas se formaron temprano o tuvieron al frente un comendador poco después de la reunión de los primeros beneficios territoriales, como por ejemplo las de Alguaire o Remolinos y sin embargo en otros sitios se configuraron décadas después de la generación de la primera célula patrimonial. En Alguaire los primeros donativos fueron de 1157, y en 1159 ya había un comendador, Raymundus de Pina, qui erat comendator Algoyra $^{43}$. Alguaire estaba en espacios recién conquistados, en tierras fértiles bañadas por el Noguera Ribagorzana, donde seguramente apremiaba el éxito de la instalación de los sanjuanistas y de su representante. La donación de Remolinos era de 1157, constando Pedro de Avratudi como comendator en el mismo año ${ }^{44}$. En sitios como Aliaga la formación de la encomienda fue un proceso más lento. Así la fortificación de Aliaga fue concedida en 1163 a los

42.- Julia PAvón, "La relación entre la monarquía y la orden de San Juan de Jerusalén en Navarra (siglos XII-XV). Un primer análisis” en J. Pavón y M. Bonet (eds.), La Orden del Hospital de San Juan de Jerusalén. pp. 131-132.

43.- J. Alturo i Perucho, Diplomatari d'Alguaire, 8 y 10.

44.- Ma L. Ledesma Rubio, Templarios, 1982, p. 129. 
hospitalarios, y se conoce la existencia de un preceptor en 1180 , tal vez ya en 1177. No obstante, la concesión de diezmos de Aliaga por parte del obispo de Zaragoza de 1181 iba destinada al Hospital y a los freires, y no parece que hubiese continuidad o estabilidad en el cargo de preceptor ${ }^{45}$. Además otros donativos en Aliaga a finales del siglo XII fueron para el comendador de Amposta o el maestre de la orden — que era el de Amposta-, y sólo en 1200 se citaba al comendador de Aliaga, Miquel de Sella y otros freires allí residentes, como el capellán, el clavero - tesorero- e incluso otro comendador llamado de Vila Roja ${ }^{46}$.

La importancia de algunas encomiendas, y en parte también de sus sedes, dio lugar a que fuesen elementos de centralización o dominación sobre ámbitos territoriales amplios. Así en la encomienda de Zaragoza se iban concentrando donaciones a mediados del siglo XII, aunque la primera referencia a comendador es de 1165. Los donativos del rey Alfonso II culminaron el desarrollo patrimonial de la encomienda de Zaragoza, donde les concedió la zuda en 1180, con clara finalidad militar y otros bienes en tierras del Jalón ${ }^{47}$. Como indica $\mathrm{M}^{\mathrm{a}} \mathrm{L}$. Ledesma, sorprende que estas tierras del Jalón se vinculasen a la encomienda de Zaragoza en vez de la de Calatayud, más próxima. Todo apunta a que, como sucedió más tarde en el caso de Amposta-Ulldecona, los sitios principales de la orden forzaron vinculaciones a sus encomiendas, pese a no ser las más "racionales" o "naturales". Así Zaragoza fue una entidad principal en la institución hospitalaria aragonesa, donde finalmente se estableció la sede de la castellanía de Amposta en el siglo XIV.

Referida la importancia de Zaragoza, conviene sólo mencionar que el asentamiento de los hospitalarios en enclaves en el valle del Ebro o sus afluentes fue muy destacado. La importancia que adquirió Zaragoza en el seno de la institución, incluso Amposta en la desembocadura del río, podrían explicarse por la trascendencia que el río ejerció a modo de eje en la territorialización patrimonial de la orden. Diversas áreas en torno a Calchetas, Mallén, Añón, Remolinos, Calatayud, la Almunia de Doña Godina — ambos en el Jalón-, Grisén, la misma Zaragoza, dominios en Pina de Ebro y Caspe reflejan la pre-

45.- L. Esteban Mateo, Cartulario, 3, 6. La referencia al comendador de 1180 en M a $^{\mathrm{a}}$ L. Ledesma Rubio, Templarios, p. 133 y en un documento de donación de patrimonio de 1177 firma Galindus, Dei gratia comendator que podría corresponder al G. de Vetula de 1180, L. Esteban Mateo, Cartulario, 5. El mismo Galindo firmaba sólo como frater al frente de otros hospitalarios al recibir más bienes en 1188, ibidem, 8. El maestre del Hospital, Fortún Cabeza obtuvo la confirmación de bienes de Aliaga efectuada por el rey en 1196, referido como representante en todo su reino en una oportunidad y obviando la vinculación con Amposta, 12, 14 y 15.

46.- L. Esteban Mateo, Cartulario, 7

47.- Ma L. Ledesma Rubio, Templarios, p. 127. 
sencia hospitalaria en las fértiles tierras centrales aragonesas ${ }^{48}$. Otros ámbitos de ribera en el Cinca o en la Noguera Ribagorzana fueron también sede de encomiendas y de amplios desarrollos patrimoniales.

Aunque el poder del comendador se fue asentando, es importante destacar que el gobierno de las instancias comendaticias estuvo vinculado a las decisiones colegiadas, y significativamente a la centralización prioral desde sus orígenes. Podemos tomar como ejemplo la concesión de tierras a censo en la encomienda de Alguaire, donde el maestre de Amposta intervino sistemáticamente junto al comendador, y otros freires ${ }^{49}$. También las cartas de población fueron libradas por el maestre de Amposta, y más tarde castellán, a menudo acompañado por uno o varios comendadores ${ }^{50}$. Las acciones de los priores en las encomiendas junto a sus comendadores, e incluso acompañados de algún otro preceptor respondían a los conceptos de autoridad central y unitaria de la institución. Además se combinaba o reforzaba con el principio de soluciones colegiadas también característico y emblemático del Hospital. Acuerdos trascendentes que afectaban al patrimonio fueron resueltos por el maestre y varios comendadores, a veces durante la celebración del capítulo provincial ${ }^{51}$. En el capítulo se atendían todo tipo de situaciones y especialmente a las patrimoniales o jurisdiccionales, como en 1216 cuando el capítulo promulgó los fueros de Aliaga o en 1254, reunido en Amposta, se establecieron derechos y deberes de los habitantes de Caspe ${ }^{52}$.

En el Pirineo Oriental, y con la sucesión de hechos políticos vinculados al reino de Pamplona-Navarra a lo largo del siglo XII, la cartografía prioral tuvo que adaptarse a un espacio bastante diferenciado con respecto a Aragón. El entramado territorial gobernado desde Pamplona había quedado alejado de

48.- Ma L. Ledesma Rubio, Templarios, pp. 128-130 y los detalles de la formación de dichas encomiendas en $\mathrm{M}^{\mathrm{a}}$ L. Ledesma Rubio, La encomienda de Zaragoza, pp. 76-79, 127-135. La donación del rey Alfonso de Caspe afectaba también a la ciudad, J. Delaville le RoulX, Cartulaire, I, p. 407. Veánse estas y demás localizaciones en el mapa.

49.- J. Alturo i Perucho, Diplomatari d'Alguaire, 35 -1175-; 89 -1189-; 98 -1197-; 105, 106, 107, 108 -1198-; 111, 114, 115, 116 -1199-; 171 -1209-; 173 -1210- y otros.

50.- M $\mathrm{M}^{\mathrm{a}}$ L. Ledesma Rubio, Cartas de población del Reino de Aragón en los siglos medievales, Zaragoza, Instituto Fernando el Católico, 1991, 105, 109, 112, 113, 114, etc.

51.- En el capítulo "general" de 1214, el maestre de Amposta concedía el castillo y la villa de Pitarcho, L. Esteban Mateo, Cartulario, 40, el capítulo de 1216, 42 y J. Delaville le RoulX, Cartulaire, II, p. 757. En las asambleas provinciales de 1214 y 1250 firmaban muchos comendadores. Otras veces, los preceptores que acompañaban al maestre y a su decisión eran pocos, y en general procedentes de la región afectada por el asunto patrimonial tratado, ibidem, 54 (1242). A veces, varios comendadores de la región podían actuar junto al maestre en la concesión de alguna renta, o su parte, como al dotar a Berenguer de Espinells con la mitad de las questias de Alguaire, J. Alturo I Perucho, Diplomatari d'Alguaire, 155 (1205).

52.- L. Esteban Mateo, Cartulario, 42. 
la frontera con el Islam — si bien acogía significativos núcleos poblacionales mudéjares en el valle del Ebro-, surcado por la ruta jacobea y sin el acceso al mar en su frontera septentrional, a partir de 1198-1200, momento en el que Castilla anexionó la fachada vascongada. Esta situación de "interioridad" de este reino hispánico, así como las pequeñas dimensiones espaciales — poco más de $12.000 \mathrm{~km}^{2}$ - además de las peculiares características socioeconómicas, mediatizaron y dieron lugar a un modelo comentaticio regional singular y aparentemente poco dinámico por su cariz rural. En principio, las rentas de la orden habrían de extraerse de pequeñas explotaciones agropecuarias, asentadas y aglutinadas asimismo sobre las más tradicionales y estratégicas áreas locales, definidas históricamente en circuitos de complementariedad económica. Estas áreas, en las que a lo largo del siglo XII se irían asentando los hospitalarios, fueron: la cuenca de Pamplona, como articuladora de los valles anexos pirenaicos, donde establecerían la sede de Cizur Menor; el valle de Aibar por el que discurría el camino de Santiago, y que organizarían inicialmente desde el foco de Leache; Tierra Estella como nudo de comunicaciones entre los espacios pirenaicos y las rutas a la Meseta, cuya sede principal fue Echávarri y, por último la ribera del Ebro, la desembocadura del río Aragón o riberas tudelanas, inicialmente focalizado por Calchetas. Entrado el siglo XIII, también hicieron su aparición las encomiendas de Ultrapuertos, sobre unas tierras atlánticas vinculadas a San Juan de Pie de Puerto y cuyas sedes serían Apat-Hospital e Irisarry ${ }^{53}$.

La inicial adaptación de la geografía comendaticia a la geografía política, trajo consigo el ajuste sanjuanista a las dinámicas y circuitos internos socioeconómicos navarros; de forma que las encomiendas pasarían a tener un perfil de irradiación comarcal básicamente rural. Este perfil fue distinto para el caso de las tierras reconquistadas en tiempos de la casa de Aragón, caracterizadas por un poblamiento concentrado en agrupaciones humanas dedicadas a la explotación de los recursos de las vegas de los ríos, y que permanecerían - con ciertas matizaciones- a lo largo de la duodécima centuria, ya en manos cristianas. Por otro lado, la ausencia de los elementos dinamizadores fronterizos, militares o de comercio a gran escala en el priorato navarro, no incidieron negativamente en el desarrollo y asentamiento del cuadro comendaticio. Más bien, la orden aprovechó y gestionó otros recursos, básicamente agropecuarios, que a la postre también les permitirían dar estabilidad a su red patrimonial y al equilibrio de sus finanzas, especialmente a partir de mediados del siglo XIV. 


\section{Proyección en las fronteras y función militar en Cataluña y Aragón}

Las conquistas de la Cataluña Nueva comportaron la incorporación del Hospital a los programas militares del condado de Barcelona, y posteriormente al resto de conquistas del reino de Aragón hasta mediados del siglo XIII. El conde, y luego el rey fueron benefactores y protectores de la orden. Dicho patrocinio regio comportó un marcado intervencionismo en el patrimonio sanjuanista en momentos y circunstancias distintas. Tal situación encajaba en el dinamismo de la institución y respondía a la prestación de servicios de la orden en pro de los intereses conquistadores y en definitiva del poder político condal o regio. En distintos documentos de donación de fortificaciones fronterizas o en tierras andalusíes del conde, y más tarde del rey de Aragón — su hijo-, se aludía a la función combativa y militar de los hospitalarios frente a los musulmanes, que constituía una locución singular entre los instrumentos coetáneos referidos a concesiones patrimoniales semejantes. Las proclamas beligerantes precedían a donativos a los hospitalarios tan importantes como Amposta en 1150, que también comprometía Oropesa aún por conquistar, la décima parte de todo lo que se conquistase a los musulmanes en 1157 junto a otros bienes, o la de los castillos de Cervera y Cullera de 1171, que se alcanzarían con las conquistas de Jaime $\mathrm{I}^{54}$. Dichos designios se tradujeron en la participación de los hospitalarios en las conquistas, y a su vez fueron compromisos para la obtención de los patrimonios concedidos. En alguna oportunidad se destacaba su importancia en la defensa y propagación de la fe cristiana y su despliegue en Oriente y Occidente en un sentido más de reivindicación funcional o de propaganda, como hizo el rey Pedro II al conceder y confirmar al Hospital una serie de privilegios en Cataluña y Aragón en $1210^{55}$. También Jaime I, poco antes de emprender la conquista de Valencia, concedió en esas tierras los castillos y villas de Torrente y Silla a los hospitalarios, indicándoles que serían "adquiridos" por ellos o por él. Esta disyuntiva entre el rey y la orden refleja cómo la institución quedaba integrada en el programa de conquista como agente del despliegue militar y beneficiada patrimonialmente precisamente por dicha acción ${ }^{56}$.

54.- J. Delaville le Roulx, Cartulaire, I, p. 295 y M. Bonet Donato, "Las órdenes militares en la expansión feudal de la Corona de Aragón”, Anales de la Universidad de Alicante, 17, (2011), pp. 248-300: pp. 262 y 264. También obtuvieron el castillo de Olocau en 1180, J. DelaviLle LE RoulX, ibidem, I, 399.

55.- J. Delaville le Roulx, Cartulaire, I, 125 y con una fórmula parecida en otra confirmación de privilegios de Jaime I, ibidem, II, pp. 300-301 (1221).

56.- J. Delaville le Roulx, Cartulaire, II, p. 448 (1233). Dicha donación se ejecutó en gran medida a favor del Hospital. 
La concesión del conde de Barcelona, Ramón Berenguer IV de Amposta con un amplio dominio en 1150, algo después de la conquista de Tortosa y en respuesta a su participación en dicha empresa perseguía establecer un enclave militar defensivo. Por eso, el mismo conde financió una fortificación para que el Hospital garantizase la defensa de la frontera con Al-Andalus de un punto estratégico en la entrada del río Ebro, fundamental para la seguridad o proyección mercantil de la vecina Tortosa y en definitiva de la cuenca del Ebro con el Mediterráneo. Según se ha visto, su dignatario de Amposta asumió la máxima autoridad de la orden en Cataluña, Aragón como prior o maestre de Amposta en el siglo XII, y finalmente castellán de Amposta ya en el siglo XIII, como Eximeno de Lavata en 1206 o Pedro de Cornellá en 1227. Sin embargo, en las décadas iniciales del siglo XIII la titulación varió de forma elocuente y también se dieron coincidencias de cargos en una persona según lo que era una característica de la orden ${ }^{57}$. Ocasionalmente, se llamó maestre en Cataluña y Aragón como hizo Pedro López de Luna en 1177, Martín de Aibar en 1200 y Fulco de Cornellá llamado magistrum in Emposta et toto regno Aragonis et in Cathalonia en $1221^{58}$. La fortificación fue la sede principal o destacada de la institución desde la segunda mitad del siglo XII, como se refleja en el hecho que el poderoso conde de Urgell quisiese ser enterrado en Amposta en 1208, donando su caballo y armas, en clara alusión a la significación militar de la orden y su sede ${ }^{59}$. Otros donativos patrimoniales o la incorporación de personas a la orden se fueron acompañando de donativos de

57.- Eximeno de Lavata era también prior de Saint Gilles en 1206, Mª L. Ledesma Rubio, Cartas de población del Reino de Aragón, 149 y José María Font Rius, Cartas de población y franquicia de Cataluña, Barcelona-Madrid, Consejo Superior de Investigaciones Científicas. Instituto Jerónimo Zurita, 1969, 251. Otras referencias a castellán de Amposta en el siglo XIII: Hugo de Fullalquer (1230); Pedro de Alcalá (1247), Mª L. Ledesma Rubio, Cartas de población, 166 bis y 171, citados como maestre en otras fuentes. En alguna ocasión, la referencia al cargo incluye posibles variantes como Hugo de Fullalquer, quien constaba en 1236 como Dei gratia magister Sancte domus Hospitalis in regnum Aragonum, Cathalonie et castellanus Emposte, Eugenio Díaz MANTECA, El "Libro de Poblaciones y Privilegios" de la Orden de Santa María de Montesa (1234-1429), Castelló, Diputació de Castelló, 1987, VI y en 1239, J. Mª Font Rius, Cartas de población, 276. Pedro López de Luna firmaba como magister Imposta in Aragona et Barchinona, Urgellensi et Pallarensis, que aludía a la dualidad institucional y política de su cargo, M. L. Ledesma Rubio, Cartas, 114 (1178).

58.- Pedro López de Luna constaba como tal y en el mismo año como maestre de Amposta, M. L. LEDESMA Rubio, La encomienda de Zaragoza, p. 510. Martín de Aibar era referido así en una sentencia arbitral con el Temple de 1200, AHN, códice 662B, pp. 31-33. Sin embargo, en documentación del mismo año constaba como maestre de Amposta, J. Alturo i Perucho, Diplomatari d'Alguaire, 121, 123, 126. La referencia a Fulco, AHN, Ordenes Militares, Orden de San Juan de Jerusalén, carpeta o c. 686, 12. Geraldo Amic era también maestre en Aragón y Cataluña en 1258, J. Ma Font Rius, Cartas de población, 303.

59.- P. DE Bofarull (ed.), Codoin, IX, Barcelona, 1853, pp. 433-6: eligo sepultura meam in hospitale de Emposta cum mille et quingentos morabetinis. 
armas y/o caballos, reflejándose así el reconocimiento de la función militar del Hospital ${ }^{60}$. En las tierras de la corona de Aragón, el término castellanía de Amposta se impuso ya en el XIII, siendo excepcional en Occidente donde se usó el distrito provincial o regional conocido como priorato y el locativo del reino. El término debió responder a la posición de vanguardia militar de Amposta que ejerció hasta 1233.

Fijándonos en el caso de Amposta, se pueden observar los procesos de crecimiento patrimonial a partir de un núcleo hasta dominar una región y las vicisitudes en la definición del sistema comendaticio. Así el distrito de Amposta se amplió con la donación por parte del rey Alfonso II el Casto de la fortificación principal de Ulldecona en 1178, con la misma finalidad de disponer de otro potente enclave militar meridional apostado en la frontera misma. Los hospitalarios debían consolidar la defensa de esta zona fronteriza, sobre todo una vez conquistada la región vecina del Matarraña o del Maestrazgo turolense y reducidos eventuales ataques desde el interior. Cabe situar esta donación en el programa más amplio del rey Alfonso de confiar la ocupación del Bajo Aragón a diversas órdenes militares, algunas claramente más favorecidas que la del Hospital ${ }^{61}$. Seguramente, la orden también fue recompensada por su casi segura participación militar en la contienda con algunas donaciones. En la zona fronteriza de Aragón, el Hospital tenía el referido núcleo inicial de Aliaga desde 1163, recibió del rey Villarroya de Pinares en 1190, y vinculada a la encomienda de Aliaga, y en sus últimas voluntades Samper de Calanda más al norte. Otros donativos en Aragón llegaron de la mano del mismo rey, como Pilluel en 1167, Torrente en 1174, Grisén en 1177 y Caspe en 1181/2, que muestran la trascendencia del patrocinio regio en la patrimonialización sanjuanista ${ }^{62}$.

Sobre Ulldecona, cabe indicar que la primera ocupación se hizo en torno a la fortificación andalusí, y los freires infeudaron el término al poderoso linaje Montcada en 1191 — también por intervención del rey—, que tuvo el dominio hasta 1241. Desde el último cuarto del siglo XII, el distrito de Ulldecona estuvo sujeto a la vecina encomienda de Amposta, existiendo un subcomendador de Ulldecona en 1239 que aparecía nombrado junto al comendador de Amposta y Ulldecona. En Amposta, desde 1157 ya había un comendador, que vivía junto y bajo la autoridad hospitalaria del maestre, quien también

60.- L. Esteban Mateo, Cartulario, 33, 36 y donación de armas y caballo, ACA, GPC, 3, 126 -1152-.

61.- Carlos Laliena Corbera, Sistema social, estructura agraria y organización del poder en el bajo Aragón en la edad media (siglos XII-XV), Teruel, Instituto de Estudios Turolenses, 1987, pp. 93-127.

62.- J. Delaville le Roulx, Cartulaire, I, p. 368 (Ulldecona); p. 357 (Grisén); p. 424 (Caspe); p. 571 (Villarroya); p. 627 (Samper de Calanda). Sobre la participación de los hospitalarios en la conquista, M. Bonet Donato, "Las órdenes", p. 270. 
residía allí. Vale la pena llamar la atención sobre el ejemplo de Ulldecona, puesto que no se convirtió en encomienda hasta muchas décadas después, y además fue objeto de infeudación. Tal acción podría ser el resultado de derechos antiguos por parte de los Montcada, beneficiados con tierras por el conde con quien mantuvieron disputas.

En todo caso, el proceso de centralización desde Amposta es evidente, puesto que a pesar de una cierta distancia con Ulldecona - a unos veinte kilómetros-, y sobre todo dada la condición estratégica principal de dicha plaza fronteriza, el comendador de Amposta regentó el dominio en el distrito ulldeconense ${ }^{63}$. Seguramente la importancia alcanzada por la comunidad hospitalaria en Amposta, jugó algún papel en dicha dependencia y la configuración de un único distrito fronterizo militar. La variedad y condición de los cargos que nos son conocidos para el convento de Amposta, se correspondía a su entidad como sede y con una destacada orientación militar. Así había un senescal, un mariscal, un camarero, un comendador de Amposta y un notario del maestre entre 1222 y 1227 , además de otros miembros ${ }^{64}$. Incluso el comendador de Amposta se llamó: preceptoris Emposte et Uldechone et totius frontari $e^{65}$. Finalmente, Ulldecona formó una encomienda ya en los años setenta y después de la pérdida de Amposta por parte de la orden a partir de la intervención del rey y a su favor, aglutinó los derechos de su vecina preceptoría desde $1280^{66}$. Este sería uno de los ejemplos de la realidad patrimonial hospitalaria sujeta en última instancia a ciertos intereses de la monarquía y finalmente intervenida por el mismo rey en su emblemática sede de Amposta. Pese a la pérdida del ámbito de Amposta, durante años se utilizó el cargo de comendador de Amposta y actuó en el amplio distrito del Montsià, unido eventualmente a Cervera en $1283^{67}$. Este ejemplo da testimonio de la existencia de un ámbito comendaticio surgido, amparado e intervenido sobre todo por los intereses políticos; aunque la institución

63.- María Bonet Donato, La orden del Hospital en la Corona de Aragón. Poder y gobierno en la Castellanía de Amposta, Madrid, CSIC, 1994, pp. 283-285. La referencia al comendador de Amposta, Pons Serras, junto al maestre, $\mathrm{M}^{\mathrm{a}}$ L. Ledesma Rubio, Cartas de población, 105 y otro Arnaldo de Sent, en 1187-90, 129.

64.- J. M M Font Rius, Cartas de población, 242 y 251.

65.- J. M M $^{\mathrm{a}}$ Font Rius, Cartas de población, 276.

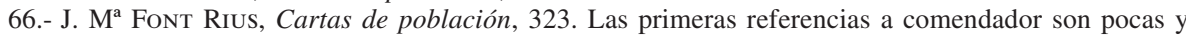
todavía predomina la intervención del castellán de Amposta en asuntos de la jurisdicción de Ulldecona, AHN, códice 662B, pp. 195-196. La intervención del rey forzó el concambio de Amposta con Onda y Gallur, J. Delaville le RoulX, Cartulaire, III, 399-403.

67.- Así era referido Guillermo de Claramonte, comendator Cervarie et Emposte, J. M ${ }^{\mathrm{a}}$ Font RiUs, Cartas de población, 348. Aparecía junto a un lugarteniente de Ulldecona, que sugiere la debilidad todavía del cargo de comendador. 
amplió en otros sitios de su interés el mapa patrimonial, como en la Aldea o en la Rápita a lo largo del siglo XIII ${ }^{68}$.

\section{Irradiación y ordenación comendaticias en Navarra}

En Navarra el mapa comendaticio fue definiéndose al compás de las donaciones recibidas y de las actuaciones de los miembros de la orden durante la segunda mitad del siglo XII, para ir diseñando una homogénea y rentable retícula patrimonial. Poco después, la configuración definitiva de la circunscripción prioral, a comienzos de la década de los setenta, acabaría por procurar, poco a poco, estabilidad a la enmarcación jurisdiccional y proyección económica de aquellas. De entre los cuatro focos que acabarían por centralizar las cuatro primigenias encomiendas navarras: Sangüesa, Cizur Menor, Calchetas y Echávarri, destacó inicialmente la primera, ya que las donaciones del Batallador los cuatro años anteriores a su muerte, además de su situación sobre un núcleo urbano del Camino de Santiago, pudieron ser determinantes para su conversión en sede de una encomienda ${ }^{69}$. Así se documenta un primer representante, de nombre Pedro Ramón en 1165 — comendator de illo Hospital de Sangossa-, mucho antes de la constatación de los comendadores de Cizur (1181), Echávarri (1187) y Calchetas (1189) ${ }^{70}$.

La posesión del palacio y la iglesia en el burgo nuevo de Sangüesa desde el primer tercio del siglo podía haberse convertido en el punto de partida para la conformación de una importante encomienda. Pero, lejos de ello, el incremento patrimonial no fue sustancial ni determinante, además de que otra serie de componentes en el conjunto de la trama geoestratégica y socioeconómica navarras arbitraron un mayor peso de otras sedes. Cizur, junto a la capital, y en la cuenca de Pamplona, y sobre la ruta jacobea, congregó la presencia hospitalaria sobre las fértiles tierras intrapirenaicas. Calchetas, en pleno valle del Ebro, albergó la casa hospitalaria en las feraces vegas de los cursos fluviales ribereños; y por último, Echávarri, próxima a Estella, encuadraría una destacada encomienda, también próxima a la ruta por excelencia de peregrinación hispana y lugar donde se documenta el primero de los capítulos

68.- La compra de la Rápita al monasterio de Sant Cugat, AHN, códice 662B, pp. 23-25 (1260).

69.- El proyecto regio de situar a los hospitalarios en Sangüesa, con la donación de su palacio, la iglesia de Santa María y distintas heredades, convirtió al núcleo en uno de los centros mejor dotados ( $P S J$, n. 6,11$)$, tanto por estructuras como por bienes complementarios $(P S J$, n. 31, 40, 79) para el desarrollo de una encomienda. Si bien, su traslado hacia la cercana villa de Leache para el siglo XIII, podría indicar la búsqueda de una optimización de los recursos y el tono de la red de encomiendas navarras, con una raigambre rural.

70.- PSJ, n. 31, 51 y 52. 
sanjuanistas navarros (1189) ${ }^{71}$. Merece la pena destacar que estos centros hospitalarios navarros de Cizur, Sangüesa o Echávarri, como sucedió con Zaragoza o Huesca, y en un cierto modo Barcelona, eran centros en creciente auge, los primeros, o localizaciones urbanas, para el caso catalanoaragonés. Un modelo y un desarrollo espacial también contrastable con la tradición benedictina o cenobítica. Las razones de la articulación territorial fueron muchas y diversas, pero la conexión con la autoridad política regia debió favorecer tales situaciones, así como su vinculación con el comercio, las vías mercantiles y la cercanía a los ámbitos tradicionales de poder, alimentada en última instancia por las necesidades o conexiones con Tierra Santa.

Como se ha referido y ejemplificado en Ulldecona, la estructura comendaticia era dinámica y adaptable; sujeta a las necesidades del gobierno central regional, y así se observa que las encomiendas en calidad de centros de distritos, dentro del priorato navarro, sufrieron las lógicas variaciones en su localización. Así en el valle de Aibar, franja de contacto con Aragón a través de la red fluvial de mismo nombre y en el margen oriental del reino, se constituyó primigeniamente la sede comendaticia de Sangüesa, tempranamente desplazada por la villa de Leache, que sería sustituida en el siglo XIII por Iracheta (una localidad cercana), y nuevamente suplantada por la mencionada Leache para las centurias bajomedievales.

Por otro lado, así como en la parte septentrional del reino, entre el prepirineo y los valles pirenaicos, se tendió a concentrar las unidades de explotación alrededor de unas pocas y estratégicas sedes comendaticias; en la parte meridional se dio un fenómeno distinto. Tradicionalmente, la historiografía se ha venido fijando en la feracidad de las tierras ribereñas, aptas para los regadíos y comunicadas con las vías comerciales del valle del Ebro hasta su desembocadura más allá de Tortosa. No obstante, la fijación de una dinámica y numerosa población sobre núcleos urbanos y rurales ciertamente importantes, así como el peso de los mudéjares, mayoritariamente encargados de los trabajos agrícolas, también influyó sobre la articulación comendaticia entre estas tierras. Así, localidades como Calchetas ${ }^{72}$, Tudela, Cabanillas, Fustiñana y Buñuel, relativamente cercanas, llegaron a convertirse en sedes comendaticias, dibujando un cuadro de gestión muy activo a nivel económico en la frontera con Aragón. De hecho Cabanillas y Fustiñana, en el margen

71.- S. García Larragueta, dedica el capítulo 3 de su estudio, El gran priorado de Navarra, pp. 85-107, al nacimiento y primera organización de las encomiendas (siglo XII).

72.- Calchetas, al igual que Cizur Menor, presenta las mismas características: un lugar estratégico cercano al polo urbano; en este caso de Tudela. Aunque para su asentamiento en Calchetas, Guillem de Belmes debió de recurrir a la compra, PSJ, n. 26. 
izquierdo del Ebro, fueron señorío del Hospital ${ }^{73}$; villas sobre las que ejerció la jurisdicción ordinaria, además de nombrar a sus alcaldes ${ }^{74}$.

El mapa de estas encomiendas albergó un número elevado de sedes, lo que invita a pensar en el peso de cada una de esas localidades microregionales, de manera que para el siglo XII se registró una red formada por 17 encomiendas; en el siglo XIII creció hasta 21; para la decimocuarta centuria la suma alcanzó la cifra de 28, disminuyendo en la centuria siguiente hasta media docena aproximadamente ${ }^{75}$. Este número de encomiendas en relación a los espacios gestionados es divergente del modelo que contemporáneamente se desarrolló en Aragón, y en gran medida también en Cataluña. Y, asimismo, dicha retícula no quedó desequilibrada por la importancia de una encomienda concreta, priorizada por las donaciones y foco de vida comunitaria; aunque cabe mencionarse Cizur por su gran actividad económica dentro de la Cuenca de Pamplona; o Calchetas en la ribera de Ebro.

Crecimiento de los dominios y de las encomiendas desde el último cuarto del siglo XII

Los hospitalarios consolidaron y alcanzaron en esas décadas finales del siglo XII dominios, y finalmente encomiendas en ámbitos fértiles de ribera tanto en Aragón como en Navarra. En el caso aragonés se consolidó en el somontano oscense, donde establecieron las preceptorías de Barbastro o de Huesca $^{76}$ y en el Bajo Cinca, en Torrente y en Sigena desde el último cuarto del siglo XII ${ }^{77}$. En ésta había una comunidad hospitalaria y la reina Sancha fundó un convento femenino en 1187, que evolucionó hacia una comunidad dúplice y disfrutó de un estatuto especial en el seno de la castellanía de Amposta, no exento de controversias con el castellán, hasta que se confirmó su independencia en 1498. En cuanto a la organización, merece la pena dete-

73.- García Ramírez entregó en 1142 las villas a la orden, PSJ, n. 18.

74.- J. PAVón, "La relación entre la monarquía y la orden de San Juan de Jerusalén en Navarra (siglos XII-XV). Un primer análisis", pp. 141 y 157-158.

75.- La interpretación de los cambios y el alto número de encomiendas en el siglo XIV está en relación con la racionalización de los recursos en un ámbito, como el navarro, de implantación rural que persigue la rentabilidad y la correcta percepción de las responsiones, Carlos BARQUero, La Orden de San Juan de Jerusalén en Navarra: siglos XIV y XV, Pamplona, Fundación Fuentes Dutor, 2004, pp. 153-154.

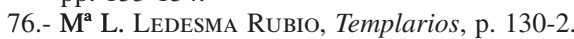

77.- M $^{\text {a }}$ L. Ledesma Rubio, Templarios, pp. 134-140; para la donación del rey Alfonso del castillo de Torrente, J. Delaville le Roulx, Cartulaire, I, pp. 316-317 (1174), y para Sigena Luís GarcíaGuiJarro, "The Aragonese Hospitaller Monastery of Sigena: its Early Stages, 1180- c. 1210" en Anthony Luttrell Helen Nicholson (ed.) Hospitaller Women in The Middle Ages, Aldershot, Ashgate, 2006, pp. 112-150. 
nerse en el hecho que la priora de Sigena gozó de una autonomía importante en el seno de la institución. Tanto era así, que el rey se dirigía a ella como priora, sin recordar su vínculo con el Hospital.

La comunidad femenina de Sigena fue trascendental para la monarquía, no sólo porque fue el lugar escogido para ser enterrada la reina Sancha, esposa de Alfonso II y su promotora, su hijo Pedro II el Católico ${ }^{78}$; sino porque fue archivo de la Corona y lugar donde la monarquía depositó sus insignias reales ${ }^{79}$. Alfonso II fue también promotor a petición de Sancha e incluso Jaime I escogió este sitio para su entierro en alguna ocasión, aunque no se llevó a término ${ }^{80}$. Esto no fue óbice para que el castellán intentase imponer una serie de restricciones a la priora como en 1226, recordándole que su cargo estaba sujeto al suyo según se había previsto en las normas de 1188, que habían fijado las condiciones de gobierno del convento femenino hospitalario ${ }^{81}$. Cabe observar cómo allí se había establecido una normativa, que refleja la excepcionalidad del priorato en el seno del sistema comendatario en formación. Tal autonomía comportó su independencia de facto del maestre o castellán y la resistencia a pagar el subsidio anual. Por eso en la normativa de 1188 y 1226 se insistía que Sigena debía pagar el subsidio anual, embrión de las responsiones a Tierra Santa ${ }^{82}$. Tal consideración refleja cómo la autonomía económica de la priora era limitada por el castellán. Entre los acuerdos de 1226 hay indicadores de la importancia del monasterio y de su priora. A ella se le obligaba a llevar un séquito de nueve monturas y dos damas, y montar con el permiso del castellán, salvo en las ocasiones impuestas por los negocios de la casa. Tenía que atender a los huéspedes, pero no podía asumir paniaguados o recibir monjas sin permiso magistral. El rey contribuyó a la autonomía de la priora, e incluso la apoyó en temas de discordia con el castellán como la recepción de religiosas ${ }^{83}$.

Retomando las múltiples situaciones que favorecieron el engrandecimiento patrimonial, cabe subrayar cómo la participación militar de los hospitalarios se premió con una serie de beneficios territoriales tras la conquista de Valencia

78.- J. Delaville le Roulx, Cartulaire, I, p. 690 (1200).

79.- Rafael Conde Delgado de Molina, "Las insignias de coronación de Pedro I-II "el católico" depositadas en el monasterio de Sijena", Anuario de Estudios Medievales, 28 (1988), pp. 147-156 y J. Delaville le Roulx, Cartulaire, II, p. 610.

80.- J. Delaville le Roulx, Cartulaire, II, p. 354 -1226-. El rey Alfonso se había comprometido a dar 3.500 aureorum Alfonsensium...ad opus monasterii de Sigena, ibidem, II, p. 94.

81.- J. Delaville le Roulx, Cartulaire, I, pp. 533-547 y J. Delaville le Roulx, Cartulaire, II, p. 348.

82.- J. Delaville le Roulx, Cartulaire, II, pp. 348-9.

83.- Ambrosio, Huici, María Desamparados, Cabanes, Documentos de Jaime I de Aragón (1263-1268), V, Zaragoza, Anubar, 1988, pp. 80-81 (1264). 
en la zona del norte de Castellón y en otros lugares valencianos. Se cumplían compromisos y promesas anteriores, como Cervera del Maestrazgo ${ }^{84}$, y Jaime I consolidaba la presencia de los freires en la región con donativos en Burriana, Sant Mateu o Càlig, que enlazaba territorialmente con su dominación en el sur de Cataluña. Se formó un gran distrito sanjuanista, aunque fueron encomiendas distintas. Otros bienes fueron librados al Hospital como Benirrage, en Alcudia, en Silla, la mitad de Cullera, Oropesa, y otros ${ }^{85}$. En esta región conquistada, las preceptorías se formaron rápidamente, donde aparecieron los cargos de comendadores. Así, en 1235 al librarse la carta de población de Cervera, ya había un comendador de nombre Dominico de Antiviana, o Raimundo de Ciri, comendador de Oropesa, junto al castellán, al comendador de la vecina encomienda de Amposta y otros como el comendador de Mallorca y el prior de Amposta. Un año antes, y por tanto sólo uno después de la conquista ya estaba el comendador en Cervera, quien libró la carta de población de Càlig ${ }^{86}$.

¿Por qué en los sitios conquistados recientemente, Cervera, Oropesa o incluso Mallorca, de poca entidad, aparecieron comendadores con rapidez? ¿Por qué concedieron cartas de población inmediatamente después de la conquista? La rapidez en la creación de encomiendas, en contraste con situaciones anteriores o incluso coetáneas con visos de flexibilidad se explica por las necesidades militares y de sometimiento de la población conquistada, que afectaron a la zona que era entonces frontera. Por eso, las cartas de población perseguían asentar a los nuevos pobladores o dominar a los ocupados.

\section{LAS ENCOMIENDAS: COMUNIDAD, TRAMA SOCIAL Y EXPLOTACIÓN DEL PATRIMONIO}

Las encomiendas fueron las células principales de la organización territorial y a pesar de este claro valor referencial fueron objeto de asociación o división en función de momentos y necesidades concretas de la orden, donde primaba la comprensión unitaria del patrimonio. Además existieron otras entidades en el marco del sistema comendaticio, como las subencomiendas

84.- Ambrosio Huici, María Desamparados Cabanes, Documentos de Jaime I de Aragón (1237-1250), II, Valencia, 1976, p. 79.

85.- Robert I. Burns, The Crusader Kingdom of Valencia. Reconstruction on a Thirteenth-century Frontier, Cambridge, 1967, p. 185 y A. Huici, Ma D. Cabanes, Documentos de Jaime I, II, p. 57-8 -donación en Alcudia, Silla y otros bienes en Albufera (1239); p. 79 (donación de casas y tierras en Denia, 1240); p. 28 (concesión de casas en Valencia a Sigena, 1238).

86.- E. Díaz Manteca, El “Libro de Poblaciones, pp. 181-183 y pp. 184-185. 
o los miembros de encomienda y más tarde los abadiatos y los prioratos. Según se ha visto, el comendador actuó a menudo sujeto o dependiente a la autoridad prioral y junto a otros comendadores o miembros de su comunidad.

Observando el ejemplo del sistema organizativo de Navarra, mejor conocido que el de Cataluña y Aragón para nuestras fechas, el prior estaba a su cabeza, y dependiendo de él un número variable de comendadores, entre los doce y veintiocho, que refleja la flexibilidad y el dinamismo del sistema comendaticio. Los comendadores, miembros de la nobleza local desde finales del siglo $\mathrm{XII}^{87}$, tanto de primer como de segundo orden, eran los encargados de gestionar y velar por la administración de los bienes, con el objeto de procurar las rentas que repercutían a la postre en el propio priorato y en el envío de las responsiones a la casa central en Ultramar. No obstante, al describir simplificadamente este esquema, aparentemente sencillo, cabría entrar a valorar no sólo el origen social de los freires navarros, sino también su papel dentro del esquema regional de la orden, su número - escaso y fluctuante, quizá entre 100 y 200 miembros-, la evolución de sus funciones, la relación con el resto de la sociedad y sus posibles implicaciones políticas como prohombres dentro de los círculos de poder ${ }^{88}$. Dichos parámetros de análisis, deberían aplicarse igualmente a la figura del prior, y más durante la etapa que se inicia en 1234, con la muerte de Sancho el Fuerte, y a partir de la cual se registran decisiones priorales estrechamente relacionadas con las circunstancias generales, ultramarinas o hispanas, así como políticas, caso por ejemplo del gobierno de los priores franceses (1270-1332) ${ }^{89}$.

Se ha citado el escaso número de miembros que componían el priorato navarro, y siempre teniendo en cuenta la complejidad de interpretación de los datos documentales. S. García Larragueta, señala que podrían ser algo menos de dos centenares para la duodécima y decimotercera centuria, cifra que Barquero Goñi hace extensiva para el resto del medievo ${ }^{90}$, suma comparativamente exigua si se toman como referencia otros prioratos. No obstante,

87.- Parece, salvo en el caso del prior, García Ramírez (septiembre, 1172-abril, 1174), que habría que esperar a finales del siglo XII para situar a hospitalarios navarros al frente del gobierno de su priorato. De hecho, a partir de 1185 y hasta 1270, los priores lucen sobrenombres locativos que les ponen en relación con ramas principales y también secundarias de familias navarras como los Chávarri, Morieta, Aldaba, Mañeru u Obanos. Estos linajes de irradiación local, sin estar situados en la primera fila de la política, poseían amplios bienes raíces y cierto prestigio social, S. GARCía LARRAGUETA, El gran priorado de Navarra, pp. 73-82.

88.- Hay que señalar, por ejemplo, el activo papel diplomático del prior Jimeno de Morieta (1196-1214) en tiempos de Sancho el Fuerte, la cercanía del prior García Artiga a Teobaldo I o las vinculaciones de Juan Jiménez de Obanos con Teobaldo II, J. PAvón, "La relación entre la monarquía y la orden de San Juan de Jerusalén en Navarra", pp. 140-141, 144-152.

89.- Op. cit., pp. 152-156.

90.- C. Barquero, La Orden de San Juan de Jerusalén en Navarra: siglos XIV y XV, pp. 118-123. 
la cantidad fue más que suficiente para articular la gestión patrimonial; sobre todo por el apoyo de la monarquía en el siglo XII y la nobleza local en los siglos XII y XIII. Sigue siendo difícil a día de hoy, conocer con detalle el funcionamiento ordinario de las comunidades sanjuanistas de fratres hasta entrado el siglo XIV, aunque se sabe de su existencia en Cizur y Bargota; o saber cuantos centros asistenciales funcionaron hasta entonces ${ }^{91}$.

\section{La trama y las vinculaciones sociales: donadores y benefactores}

La gestión de las encomiendas comportó desde un inicio la ampliación de los dominios mediante compras, apropiaciones, donaciones de particulares, que a veces conllevaron vinculaciones personales con la poderosa institución. El proceso afectó al primer siglo de la implantación del Hospital y sólo se prolongó en lugares concretos. Sin embargo, hubo momentos de especial crecimiento del patrimonio sanjuanista, como las últimas décadas del siglo XII en Aragón, en ámbitos de Cataluña y también en Navarra ${ }^{92}$ cuando los llamados redondeos se acompañaron y coincidieron con el aumento de donados y miembros de la orden ${ }^{93}$.

El patrimonio de una entidad comendaticia aumentó de diversas maneras y algunas personas afectadas por el despliegue de la institución quedaron unidas espiritualmente a la orden y al entramado social dependiente de la misma. La pérdida de los derechos de propiedad o tenencia por parte de benefactores de la institución fue compensada mediante diversas fórmulas de asociación con el Hospital. Estas favorecieron los donativos y paliaron las consecuencias negativas para quienes se desprendían de su patrimonio. Sin duda, la mayor parte de las soluciones reflejan un cambio social por parte de los donadores, quienes a título personal obtenían alguna condición o prerrogativa para hacer frente a la pérdida de parte de su fuente de riqueza e incluso en algún

91.- Se documentan, para esta etapa, los hospitales de Cizur, al parecer destinado principalmente a los freires ancianos y enfermos del priorado, y Bargota. También se sabe de la existencia de las comunidades conventuales de Bargota, Buñuel, Cabanillas, Casanueva, Cizur, Echávarri, Falces, Iracheta y Leache, todos ya en el siglo XIII, S. García Larragueta, El gran priorado de Navarra, pp. 247-249.

92.- Julia PAvón y Ángeles García de la Borbolla, "Hospitalarios y Templarios en Navarra. Formación patrimonial (1134-1194)", Las Ordenes Militares en la Península Ibérica. Edad Media, Cuenca, Ediciones de la Universidad de Castilla-La Mancha, 2000, pp. 571-587.

93.- $\mathrm{M}^{\mathrm{a}}$ L. Ledesma Rubio, La encomienda, p. 52. En la encomienda catalana de Siscar, de 1160, se aprecia dicho crecimiento patrimonial en el último cuarto del siglo XII, Jordi BoIX PocIELLo, "Els ordes religioso-militars a la franja de Ponent", Actes de les primeres jornades sobre els ordes religiosomilitars als països catalans (segles XII-XIX), Tarragona, Diputació de Tarragona, 1994, pp. 132-153: pp. 207-209. En este caso, las medidas para captar bienes lograron terminar con la "pobreza" de la casa. Muchas donaciones y adquisiciones ampliaron el patrimonio de la encomienda de Sant Valentí de Vilafranca en estas fechas, J. Miret i SAns, Les cases de Templers y Hospitalers, pp. 120-124; o en el Pallars, ibidem, pp. 135-136. 
caso de su totalidad. El pago de una compensación monetaria por parte de la orden a quien había contribuido con una dádiva patrimonial refleja el empeoramiento de las condiciones económicas del benefactor, o al menos la provisión de cierto nivel de resarcimiento. La compensación se llamaba de manera elocuente "limosna o caridad", como los veinte morabetinos que Rodrigo y Urraca obtuvieron al confirmar una viña en Codo al Hospital ${ }^{94}$. De todos modos, el mismo término se usaba para referir algunas donaciones efectuadas a la institución.

Otro conjunto de donativos al Hospital obtenidos en sus múltiples establecimientos patrimoniales o comendaticios de las primeras décadas concitaron fórmulas de protección transitoria a favor de los benefactores. Esto se llevó a término al demorar la ejecución de la integración del bien al patrimonio sanjuanista previsto en ciertas donaciones votivas mediante las llamadas donationes post obitum ${ }^{95}$. Los donadores podían disfrutar del bien hasta su muerte, aunque en ocasiones debían contribuir con una renta, como los dos cahices de cereal, que Pedro Sobrino y esposa comprometían en su donación post obitum de una heredad en Huesa. Se especificaba que la renta era de recognitione y daba testimonio de la dependencia adquirida por los donadores con la orden al perder sus derechos ${ }^{96}$. Incluso algún benefactor fue compensado con otros bienes como la cesión vitalicia de la iglesia de Campos obtenida por Adán de Alcalá sujeta a rentas y tras haber donado un tercio de todo su patrimonio ${ }^{97}$. En otras oportunidades, los donantes obtenían el derecho a trabajar las tierras que habían sido de su titularidad, como sucedió con Pedro Forbidor y su esposa que libraron sus tierras de Zaragoza a la orden en una típica donatio reservato usufructo en $1157^{98}$. Era uno de los procedimientos manejados por

94.- L. Esteban Mateo, Cartulario, 8 (1188) o los setenta sueldos obtenidos por los hijos de Lope de Arándiga al conceder su molino, M ${ }^{\mathrm{a}}$ L. Ledesma Rubio, La encomienda, p. 536, 144 (1214). Diecisiete sueldos obtuvo un matrimonio tras hacer un donativo al Hospital de Vilafranca, J. MiRET I SANS, Les cases de Templers y Hospitalers, p. 120 (1167).

95.- M $\mathrm{M}^{\mathrm{a}}$ L. Ledesma Rubio, La encomienda, 7: es una donación post obitum de una viña efectuada por Roberto Monje y esposa en 1165; y otros ejemplos en p. 508, 7 (1156); p. 509, 13 (1176); p. 214, 23 (1176); p. 217, 28 (1177) o J. Alturo, Diplomatari d'Alguaire, 261 (1227). Es el caso de Fortunio de Barbatáin en la cendea de Galar, cercana a Cizur (1167); Sancho Sobrino en Gordués (1160), $P S J$, n. 34, 40 .

96.- L. Esteban Mateo, Cartulario, 7 (1183). Otro testimonio de pago de censo tras el donativo, $\mathbf{M}^{\mathrm{a}}$ L. Ledesma Rubio, La encomienda, 27 (1177). En alguna ocasión, tan sólo se especificaba que los benefactores quedaban como tenentes y que tras su muerte, los bienes pasaban definitivamente a la orden, como A. y su esposa María, quienes recibieron sepultura en la orden, L. Esteban Mateo, Cartulario, 46 (1214-1220).

97.- L. Esteban Mateo, Cartulario, 20 (1202). Una donación de bienes muebles por parte de J. Escolano fue compensada vitaliciamente con la cesión de una heredad en Santiella del Hospital, ibidem, 33 (1211).

98.- Ma L. Ledesma Rubio, La encomienda, 4. 
la orden para paliar el cambio socioeconómico que se avecinaba al donador ante la futura pérdida de los derechos patrimoniales y que cubría las necesidades de los donadores en vida.

Entre los benefactores de bienes al Hospital, destacan los que quedaron vinculados como beneficiados, donados o confratres. Así en las encomiendas de Aliaga (Aragón), Echávarri, Cizur, Calchetas y Bargota (Navarra), dichas donaciones referidas a veces como limosnas reportaron beneficios espirituales, como el derecho a ser enterrados en su cementerio, común a otras sedes de la institución ${ }^{99}$. Otros promotores, menos en número en relación a los recibían sepultura, quedaron ligados a la institución de maneras variadas, pero no como freires, sino a lo sumo como fratres speciales ${ }^{100}$. A veces, la persona vinculada era recibida con sus bienes como "beneficiada", y por tanto cabe pensar que quedaba sujeta a un estatuto de protección, pero no completamente integrada a la comunidad conventual como caballero o freire $^{101}$. En la aceptación de un matrimonio como beneficiados, se especificaba que dispondrían de bienes sicut unus fratrum nostrorum; por tanto, quedaban unidos en cuanto a la disponibilidad material como si se tratara de un freire, pero no eran recibidos como tales ${ }^{102}$. En la admisión de Guillem de Salanova como beneficiado hacia 1214 , se identificaba su categoría con el término "donado", y se indicaba que podría integrarse o bien a la casa de Vallmoll o a la de Amposta. Sin embargo, asimismo se estableció que podría tomar el hábito, la cruz, aportando sus armas, y situándolo inequívocamente

99.- PSJ, n. 66, 122, 161 y 201-202, para Echávarri, Cizur, Calchetas y Bargota, respectivamente.

100.- Algunos testimonio de beneficiados que deberían recibir sepultura en la orden, L. EsteBAN MATEO, Cartulario, 20 (1202), 30 (1209), 53 (1234). Más genéricamente, algunos legados en Alguaire se acompañaban de la donación del "cuerpo y el alma”, J. Alturo, Diplomatari d'Alguaire, 133 (1202) y otros benefactores obtenían explícitamente el derecho de ser enterrados e incluso se detallaba que la orden tendría encendida permanentemente una lampadem ardentem, como, por ejemplo, para Pere de la Clusa en el altar de santa Maria de Alguaire, ibidem, 209 (1217); Guillem Berenguer también sería enterrado en la casa de Alguaire, 280 (1320). Hubo una variedad de fórmulas en la vinculación a la orden sin ser miembro pleno o freire de la comunidad conventual, pero en una categoría inferior o distinta, como el matrimonio integrado como "freires especiales", ibidem, 25 -1206-. En otros no se puede concretar cómo quedan vinculados al Hospital, 33 (1211), 50 (1200?). Para Navarra, por ejemplo, Pedro Guillem Palmer hizo testamento quam intraui in Hospitali, PSJ, n. 157 y 158 (1215); Iñigo Ortiz y su esposa, Inés Zapata, entregaron a la casa de Calchetas la villa de Erviti al deuandito Hospital ena entrada de nostra orden, por remisión de nostros peccados, PSJ, n. 388 (documento fechado c. 1260).

101.- L. Esteban Mateo, Cartulario, 39 (1214): Oria pasaba a ser beneficiada de la encomienda de Aliaga.

102.- L. Esteban Mateo, Cartulario, 47 (1214-1220). El compromiso de la orden de provisión de alimento y vestido a los donadores era para este tipo de beneficiados, $\mathrm{M}^{\mathrm{a}}$ L. LeDEsma Rubio, $L a$ encomienda, p. 516, 42 (1185). Es el ejemplo también del matrimonio formado por Iñigo y Jordana, PSJ, n. 127. 
como caballero en esta segunda posibilidad ${ }^{103}$. Por tanto, las categorías de los eventuales miembros de la institución estuvieron también sujetas a cierto dinamismo o variabilidad, como en este caso que se contemplaban como posibles dos categorías y dos comunidades para Guillem de Salanova. Se llegó a especificar que la condición de ser miembro de la orden comportaba que los bienes y persona del concedente quedasen "bajo la custodia y protección de la orden" como en la aceptación de confratres. La categoría de confratre era la más próxima a ser miembro de la orden, como Pedro Garcés Almoravid (1192) o Juan Martínez de Mañeru, futuro prior (julio, 1240-abril 1250), quien hacia 1230 se había entregado como donado, junto con su hija, o Elvira Íñiguez de Sada ${ }^{104}$; de hecho, algunos donadores quedaron sujetos a la orden con esta cláusula ${ }^{105}$.

La protección convenida con los donadores por el Hospital resolvía la situación vital o vitalicia de los afectados por la pérdida patrimonial, y afectaba sólo y como excepción a algunos miembros de la familia amén de los donantes. Así en 1172, una dádiva comportaba que el hijo del concedente, Lupo, sería miembro de la orden, confratre, y precisaba que los hospitalarios debían enseñarle a leer. El amparo se extendía en este caso a la madre de su hijo, que recibiría vitaliciamente una renta anual procedente de la heredad concedida o bien su cuarta parte ${ }^{106}$. Juan de Collato y su hijo Domingo Juan se entregaron a la orden con su patrimonio, aunque su hijo afirmaba que podría disfrutar de los bienes de su padre en caso de morir después. No obstante, deberían pagar anualmente una renta y el padre encomendaba a sus otros dos hijos a la orden hasta la edad de doce años, dejándolos luego bajo "el consejo y la ayuda" del Hospital ${ }^{107}$.

103.- J. Alturo, Diplomatari d'Alguaire, 189.

104.- Pedro Garcés se entregaba al Hospital quod ego non habeam potestatem transferendi in alia religione nec in vita nec in morte; y Juan y su hija nos damos a Dios e al santo Hospital de sant Johan e a los seynores malaptos d'Ultramar, vivos e sanos e stando en nuestra buena memoria e si nos ambos en vida orden oviemos de prender que prengamos la orden de sant Johan (PSJ, n. 70 y 232). Elvira Íñiguez se entragó como donada, encara prometo que si io quisiere recebir nuilla orden que reçiba el habit del Hospital et non otro (PSJ, n. 515, fechado en Echávarri el 5 de mayo de 1290).

105.- La orden recibió a Bela, en los términos siguientes: damus vos...panem et quam in domo Hospitalis tanquam uno donato, L. Esteban Mateo, Cartulario, 36 (1211). El referido Bela daba sus bienes quam frater Hospitalis sim. Había una percepción distinta entre Bela, quien pensaba que sería freire y la orden que lo acogía como a un confrare. También fue recibido como confratrem et amicum Bernat Martí de Almacelles, y amparado según la fórmula mencionada, J. Alturo, Diplomatari d'Alguaire, 203.

106.- M M $^{\mathrm{a}}$ L. Ledesma Rubio, La encomienda, 15. La condición de confrare de su hijo se planteaba en el testamento, así como las previsiones precisas de su incorporación al Hospital, segura hasta los veinte años, quien alcanzada dicha edad podría decidir su continuidad o no, ibidem, 17.

107.- Ma L. Ledesma Rubio, La encomienda, 21 (1176). Las palabras escogidas, vivant cum consilio et adiutorio, aluden a vinculaciones de dependencia vasallática, que sin ser el caso, sirven para expresar la condición de dependencia que la familia ha adquirido en favor del Hospital. 
Un número menor de donaciones, en general importantes, conllevó la vinculación del benefactor a la orden, como Sancho de Tarazona, quien concedió el dominio de Aliaga y otros bienes en 1163, vinculándose como fratre in vita et in morte. Además explicitaba que tomaba la cruz, en clara alusión al sentido cruzado de la institución ${ }^{108}$. De forma parecida, Ramon de Siscar concedió una "dominicatura" en Alguaire, fijada en rentas agrarias en 1192, y se acordó la posibilidad de que fuese freire caballero del Hospital. Puede interpretarse como una solución de "amparo" puesto que su donación comportó el pago de una suma por parte de la institución, ya fuese movido por alguna necesidad o respondiendo al interés de ampliación patrimonial de la institución ${ }^{109}$.

Otras vinculaciones a la orden fueron de carácter colectivo, como sucedió con la comunidad cristiana de Grisén en 1178. Conforme al documento, los habitantes cristianos se entregaron con sus bienes, casas y heredades, al Hospital con el fin de quedar bajo el amparo de los freires y sujetos a su "defensa", explícitamente en la paz y en la guerra. Además se detallaba que si un cristiano era objeto de ataque o prejuicio por parte de un musulmán, la orden lo detendría y castigaría ${ }^{110}$. Cabe advertir como la orden del Hospital era percibida como garante de la "paz" o de la protección de una comunidad. En este caso es fácil imaginar tensiones entre musulmanes y cristianos en Grisén, y en ese contexto la "voluntaria" vinculación de los cristianos a la orden. La preferencia o la preeminencia de la protección a los cristianos es evidente porque hasta 1211, la aljama no recibió la "amparancia" del Hospital $^{111}$. Ambas referencias aluden a la especificidad de la institución como orden militar y en especial a las funciones que socialmente se le reconocían, y que desarrollaron en sus patrimonios.

Los múltiples procesos de donación y vinculación personal o familiar a la "trama social" de la institución en expansión eran el resultado de acuerdos, forzados a veces por la necesidad, por las estrategias de consolidación patrimonial del instituto y no siempre asumidos por los "benefactores" 112

108.- L. Esteban Mateo, Cartulario, 2.

109.- J. Alturo, Diplomatari d'Alguaire, 73.

110.- AHN, códice 650, p. 311, n. 258 y M. L. Ledesma Rubio, Cartas, 112 (1178). Explicitaba que la protección les amparaba de la guerra de reyes. Como no podía ser de otro modo quedaban sujetos al pago de un censo.

111.- AHN, códice 650, p. 383, n. 347 y Mª Luisa Ledesma Rubio, «Colección diplomática de Grisén (siglos XII y XIII)», Estudios de la edad media de la Corona de Aragón, volumen X, Zaragoza, 1975, pp. 691-808, y p. 744. Se comprometen a defenderlos "como sus hombres y vasallos".

112.- Conocidos son los casos de donaciones efectuados a instituciones religiosas por haber contraído una deuda como sucedió a Ferrara con el Hospital, Mª L. Ledesma RubIo, La encomienda, p. 516, 44 (1186). 
Hay testimonios en esta dirección como la negación de la donación del molino de Canava por parte de Blasco de Cabañas en 1182, o la reformulación de convenios con mejores compensaciones para los donadores, que advierten de la resistencia ante la ampliación patrimonial de los hospita$\operatorname{larios}^{113}$. Muchos fueron los pleitos judiciales que la institución afrontó para fijar su patrimonio en todos los territorios del tercio oriental hispano a lo largo de los casi dos siglos primeros de su establecimiento, y en especial durante la primera centuria de presencia solariega. Se trata de uno de los testimonios más elocuentes acerca de la compleja realidad del crecimiento de recursos y bienes, y que merecería, en otra ocasión, una atención monográfica.

\section{La funcionalidad de la rama femenina}

La variedad de vínculos personales que las comunidades sanjuanistas fueron desarrollando con las sociedades locales al paso de su crecimiento tuvieron su correlato en las comunidades conventuales, que fueron cambiantes en su organización, liderazgo y gobernanza. Resulta elocuente de la estrecha conexión con las aristocracias locales o regionales el florecimiento de la rama femenina y su encaje con las comunidades masculinas, como se puede observar con los monasterios de Sigena y Cervera. En el priorato navarro no se documentará ninguna corporación de mujeres similar — si bien no con el mismo alcance- hasta el siglo XIV, con el convento Bargota $^{114}$.

La primera de las comunidades femeninas en los territorios hispanos fue fundada en Grisén en 1177 por el rey Alfonso II, seguramente a instancias de la reina Sancha ${ }^{115}$. Una vez más, la monarquía patrocinaba una nueva fórmula en la orden que tendría gran trascendencia. En Grisén, doña Maior congregó unas cuantas socias según decía el diploma del rey, y las estableció específicamente bajo su protección y defensa. En ese sentido, dejaba claro que el maestre y los freires no debían intervenir en el patrimonio de las dominas ni permutarlo, permaneciendo ellas allí. La comunidad, como sucedería con Sigena se forjó bajo una fuerte protección regia y Alfonso II garantizó explícitamente la autonomía de las hospitalarias en relación con los freires ${ }^{116}$. Con todo, y como sucedió en muchos otros centros femeninos de la orden, se desarrolló una comunidad dúplice y las relaciones con los freires o autoridad

113.- Ma L. Ledesma Rubio, La encomienda, p. 514, 32 (1182); 34 (1183); p. 522, 76 (1195).

114.- C. Barquero, La Orden de San Juan de Jerusalén en Navarra: siglos XIV y XV, pp. 124-128.

115.- M ${ }^{\mathrm{a}}$ L. Ledesma RuBio, La encomienda, pp. 132-135.

116.- AHN, códice 650, p. 310-311, n. 257. 
masculina fueron cambiantes ${ }^{117}$. En los años siguientes, doña Maior intervino en diversas transacciones, en general junto al maestre de Amposta, llamándose priorise de Ricla et usque ad flumen Yberis, o como nobilissima o sorore, como por ejemplo en la concesión de las cartas de población de la Almunia de Doña Godina y de Alpartir, junto a los freires ${ }^{118}$. Su carisma mantuvo una especial autoridad en los primeros años de su gobierno, y en 1184 o 1191 el oficial local era el comendador de Grisén, quedando luego dicha dominación bajo la órbita de la encomienda de Zaragoza.

Otros testimonios catalanes muestran momentos de liderazgo en manos de la comendadora/priora, incluso proyectado o ejercido en la comunidad masculina. Tal preeminencia estuvo a menudo relacionada con el carisma, o si se prefiere fue el resultado de la condición social destacada de la comendadora. En la comunidad femenina de Cervera (Lérida), su priora, Marquesa, llegó a estar al frente de la comunidad masculina, y cuando ella administró el poder comendatario, al frente de la comunidad de freires hubo un lugarteniente de comendador, o más tarde subcomendador ${ }^{119}$. Dichos cargos estuvieron sujetos a la autoridad de Marquesa y actuaron por mandamiento de ella, quien de hecho reunió más poder incluso que un preceptor. En 1245, las autoridades del Hospital concedieron a Marquesa una serie de prerrogativas, excepcionales en las fórmulas de gobierno de la orden, que le permitían aceptar freires, monjas y donados, e incluso nombrar un comendador ${ }^{120}$. Era una situación singular y prevista sólo en relación a su persona, puesto que tras su defunción, el castellán decía claramente que nostri auctoritate possimus recuperare. Sin embargo, en una segunda concesión de Cervera a Marquesa, su hija Gueralda fue confirmada como su sucesora al frente de la comunidad, y dicha solución refleja el alcance del poder de su madre ${ }^{121}$.

117.- Para la evolución de las vinculaciones entre el poder del comendador y la priora de Sigena, véase Antonio Ubieto, El real monasterio de Sigena (1180-1300), Valencia, Anubar, 1966, pp. 25-30.

118.- La primera referencia en la referida vinculación de los cristianos de Grisén y M $\mathrm{M}^{\mathrm{a}} \mathrm{L}$. LEDESMA RUBIO, Cartas, 113 y 114 (1178), respectivamente.

119.- J. Miret I SAns, Les cases de Templers y Hospitalers, pp. 214-215; 208-209 y Maria Bonet, «Els hospitalers en temps de Jaume I», Maria Teresa Ferrer Mallol (ed.), Jaume I. Commemoració del VIII centenari del naixement de Jaume I, volumen II, IEC, Barcelona, 2013, pp. 339-361: pp. 352-354.

120.- Jesús Alturo i Perucho, Diplomatari d'Alguaire i del seu monestir duple de l'orde de Sant Joan de Jerusalem (1245-1300), Barcelona, Fundació Noguera, 2010, 1. Con todo, se indicaba su dependencia con el castellán de Amposta, el cumplimiento de la visita al capítulo y la satisfacción de las responsiones. Algunas acciones del subcomendador bajo su autoridad, 3 y 4 (1245); 27 (1250).

121.- J. Alturo i Perucho, Diplomatari d'Alguaire i del seu monestir duple... (1245-1300), 23 (1248). En esta oportunidad, el castellán de Amposta rectificaba sobre la primera versión de la concesión de Cervera, y le confirmaba la comunidad de seis monjas, prohibiendo cualquier incremento de la misma. 
El protagonismo de Marquesa fue tal que en un capítulo provincial pidió el traslado de su comunidad femenina. Se le concedió el establecimiento en Alguaire en 1250, donde había una comunidad masculina ${ }^{122}$. Fue entonces referida como comendadora de Cervera y Alguaire, aunque en las decisiones se acompañó de freires y monjas, y no mucho después, en 1266, había un comendador en Cervera, todavía dependiente o vinculado con Marquesa ${ }^{123}$. Todo apunta a que Marquesa alcanzó un poder muy destacado debido a sus orígenes familiares, puesto que era miembro de una familia muy notable, los Cervera, y sobre todo ella fue una destacadísima benefactora de la orden del Hospital $^{124}$. En la comunidad dúplice de Isot, en 1261, menos documentada, también hubo una comendadora al frente de la comunidad femenina y de la masculina ${ }^{125}$.

Las comunidades femeninas desplegaron tareas asistenciales, y su formación en el marco de una encomienda masculina era justamente para atender a peregrinos o enfermos como sucedió con la congregación de donadas en la encomienda de Siscar a inicios de los años ochenta del siglo XII. Las monjas o donadas tuvieron también un destacado protagonismo en los asuntos de esta encomienda, y lo que es más importante, los miembros de la aristocracia local las tenían en una destacada consideración ${ }^{126}$.

El convento femenino de Bargota, que florecerá entrado el siglo XIV, situado en la ruta jacobea y en las proximidades de Estella, también pudo tener una fundación o apoyo inicial regio; si bien los testimonios históricos documentales impiden aclarar en qué momento y bajo qué condiciones tuvo lugar el asentamiento conventual ${ }^{127}$. No obstante, y a pesar de la lejanía con los modelos aragoneses, en Navarra también hubo constancia de la existencia de seroras, nomenclatura aplicada por S. García Larragueta ${ }^{128}$, o freiras. De hecho, este autor manejó la hipótesis — por otro lado, nada inverosímil— de la posibilidad de que el conocido como monasterio de Dueñas de Barañáin,

122.- Josep Maria Llobet I Portella, "La comanda hospitalera de Cervera durant els segles XIII, XIV i XIV" segons una carta de Jaume Pasqual (1788)", Actes de les primeres jornades sobre els ordes religioso-militars als països catalans (segles XII-XIX), Tarragona, Diputació de Tarragona, 1994, pp. 302-312; pp. 304-305 y Joaquim Miret I SANs, Les cases, pp. 552-554.

123.- J. Alturo i Perucho, Diplomatari d'Alguaire i del seu monestir duple... (1245-1300), 36, 37 (1252); 38, 39 (1252), para citar algún ejemplo y comendador, 117, 127.

124.- J. Alturo i Perucho, Diplomatari d'Alguaire i del seu monestir duple... (1245-1300), 113, 116 -1266-, entre otros testimonios.

125.- J. Miret I SANS, Les cases de Templers y Hospitalers, p. 211.

126.- J. Boix Pociello, "Els ordes...", pp. 207-209.

127.- AHN, Órdenes Militares, leg. 8568, n. 109, el texto relata que la comunidad femenina había sido fundada por la reina María (1338-1347); y que quizá se puede identificar con la hija de los reyes Felipe III y Juana II que se casó con Pedro IV el Ceremonioso.

128.- S. García Larragueta, El gran priorado de Navarra, pp. 103-107. 
y que acabaría conformando el núcleo religioso de San Pedro de Ribas, albergara alguna comunidad de sanjuanistas; si bien a día de hoy sigue sin poderse hacer ninguna afirmación concluyente. Aún con todo, los diplomas recogen también una variedad de realidades y vinculaciones de dependencia femeninas para con el Hospital, similares a las de las situaciones de los donados y que invitan a pensar también en beneficiadas, donadas o confratres ${ }^{129}$.

Desde mediados del siglo XIII en ámbitos catalanes, aragoneses y navarros, los donativos procedían de la aristocracia local, coincidiendo con el fin del patrocinio regio. En los ejemplos vistos de Cervera y Alguaire, algunas viudas de familias de la nobleza local o regional fueron benefactoras e ingresaron en las comunidades. Ambas situaciones muestran como la inserción de la orden en las realidades aristocráticas locales, y muy claramente en la rama femenina, propiciaron un mayor arraigo del Hospital en el medio aristocrático regional, distinto que el desarrollado por otras órdenes militares. La pluralidad funcional del Hospital y la identificación y soporte de esta realidad, por parte de la sociedad local o regional, contribuyeron a la viabilidad y refuerzo de la institución tras la pérdida de Tierra Santa.

\section{Explotación del patrimonio}

La explotación del patrimonio respondía a un amplio proyecto que abarca factores variados y variables. Así ese conjunto de actuaciones gestoras que englobaban, a saber: la recepción de dádivas territoriales y derechos dominicales, el control de los espacios productivos, la exacción ordenada de los recursos, la obtención de recursos extraordinarios, la mejora y racionalización del patrimonio, además de la compensación de las posibles pérdidas, se articularon distintiva y desigualmente en este amplio lapso temporal de los siglos XII y XIII, y sobre las diferentes áreas comendaticias. Sirva como testimonio de dicha variedad, las tierras del Pirineo Occidental y Oriental, sobre las que se desplegó el patrimonio del priorato de Navarra o incluso en Cataluña, que presentaban, en principio, una realidad socioeconómica similar a la existente en otras regiones hispanas lejos del control musulmán a comienzos del siglo XII. Este escenario, que tradicionalmente se encuadra

129.- La primera de las donadas navarras figura con su marido Iñigo Fortuñones (PSJ, n. 32, de 1167), y la que parece primera serora es Maria Enric, quien recibe, con el resto de la comunidad, como donado del Hospital a Fortunio Barbatáin, PSJ, n. 34, c. 1167. Otras mujeres ingresarán en la orden, caso de Navarra o de Oria Guerra, venerabili sorore nostre, PSJ, n. 80 y 98, de 1195 y 1198. Tal y como se conoce para otros ámbitos de las órdenes, Helen Nicholson, "Women in Templar and Hospitaller Commanderies", en A. Luttrell y L. Pressouyre (dirs.), La Commandarie, institution des ordres militaires dans l'Occident médiéval, París, éd. du CTHS, 2002, pp. 125-134; p. 127. 
en el amplio marco señorial, social y jurídicamente complejo, presuponía que la base de la obtención de rentas, y en definitiva de la economía, giraba en torno a la explotación de los recursos agrarios.

La explotación de los bienes del Hospital se llevó a cabo mediante los establecimientos a censo o heredades a censo en las tierras de la corona de Aragón y Navarra, aunque otras modalidades como las cartas de población fijaron las condiciones en determinados ámbitos y con las comunidades campesinas. A menudo las cartas respondieron a las necesidades de impulsar el poblamiento o fijar la residencia de los campesinos, y establecieron el marco general de los requisitos de la explotación agraria. Junto a los compromisos derivados de estos contratos, otras rentas completaban las obligaciones campesinas. En este sentido, en el priorato navarro, el sistema de explotación articulado para la gestión y rendimiento del patrimonio se basó en la carga censal anual: censos, pechas o tributos, como reflejan los textos documentales ${ }^{130}$. Así lo afirmó, en su día, S. García Larragueta, quien al caracterizar los modelos económicos de la orden para los siglos XII y XIII, indica que se ven como notas dominantes el fraccionamiento de la propiedad, muy repartida, y el régimen señorial atenuado y convertido en un sistema de explotación a base de censos anuales ${ }^{131}$. Esta definición de la realidad de la explotación del patrimonio, aparentemente simplificadora, sigue precisando, en cierta forma y a pesar de los nuevos análisis temáticos y revisiones historiográficas, el sistema dominial bajo la potestad directa e indirecta del Hospital.

Los censos reclamados se inspiraban en las prácticas y tradiciones locales. Así en tierras centrales de Cataluña, como por ejemplo en las administradas por la encomienda de Sant Valentí de Vilafranca la exigencia del censo era del cuarto o en algún caso del quinto de la cosecha, aunque en la misma zona, en una masía concedida al matrimonio formado por Pedro Bernardo y Arsenda, éstos pagaban un par de capones y una medida de cebada junto al cuarto en $1152^{132}$. En la encomienda de Siscar, el comendador concedió una explotación - capmàs - , sujeta al pago anual de un sexto de los cereales, un tercio del vino y la mitad de la fruta y de los productos de huerta ${ }^{133}$. Estas fórmulas se

130.- Esta realidad queda reflejada en los textos diplomáticos: PSJ, n. 116, 185, 280, 289, 290, 293, 300 , $320,323,331,342,345,346,349,362,372,379,386,390,392,407,408,412,413,436,439,442$, $462,484,511,515,516,531,549,550,555$ y 554.

131.- S. García Larragueta, El gran priorado de Navarra, pp. 183.

132.- J. Miret i SANS, Les cases de Templers y Hospitalers, pp. 146-147.

133.- J. Miret I Sans, Les cases de Templers y Hospitalers, p. 125. Otros ejemplos muestran la coincidencia de pagos a proporción y alguna renta fija como en un honor de la encomienda de Lérida, que estaba sujeto a la novena de los frutos, tres pernas y tres fanegas de cereal (1175), ibidem, p. 189. También en el siglo XIII, ACA, GPC, 15, 235 (1272 en Pallars). 
registraron en ámbitos conquistados en el siglo XII también ${ }^{134}$. Además las exigencias de parte de cosecha se aplicaron, a su vez, a comunidades agrarias a partir de la carta de población, como la petición del tercio a los labradores de Torrente de Cinca en $1176^{135}$. En los contratos agrarios ad plantandum de encomiendas aragonesas se llegó a repartir las rentas ad medietatem ${ }^{136}$.

Junto a esta modalidad de pago de rentas sobre la cosecha, se desarrolló y finalmente estabilizó la percepción de rentas fijas por parte de la orden durante el siglo XIII. Dicha fórmula era más ajustada a la realidad financiera de la orden, necesitada de sumas estables para contabilizar y pagar las responsiones ${ }^{137}$. Esto coincidía con el proceso de superación de tipos de renta más irregulares, y contestadas por la población como por ejemplo las "peytas". En Caspe, las rentas arbitrarias, "peytas" y "questias", se transformaron en un pago anual de 300 sueldos en 1254, al parecer tras la negociación con el consejo de la localidad ${ }^{138}$. En muchos "establecimientos" catalanes o contratos agrarios, se fijaba una cuota anual en metálico, aunque a veces se especificaba su posible satisfacción en especie ${ }^{139}$.

\section{Los dependientes en la explotación dominial: las comunidades musulmanas y los collazos}

Otro de los aspectos destacables en la explotación agraria del patrimonio sanjuanista fue el recurso a la utilización de los sometidos musulmanes como exaricos y mediante otras fórmulas aplicadas a las comunidades mudéjares. Esto era el resultado de la ocupación de ámbitos de persistencia de pobla-

134.- J. Alturo, Diplomatari d'Alguaire, 66 -1188-. Un matrimonio recibió una viña sujeta al pago del cuarto.

135.- Ma L. Ledesma Rubio, Cartas, 105. Para las tierras de secano, los hospitalarios exigían sólo la novena y el cuarto para prados y sotos.

136.- M M $^{\mathrm{a}}$ L. Ledesma Rubio, La encomienda, pp. 172-173.

137.- En este sentido la concesión de heredades a censo fue el sistema predominante en la encomienda de Zaragoza en la segunda mitad del siglo XIII, ibidem, pp. 174-175.

138.- Ma L. Ledesma Rubio, Cartas, 194. El consejo era el responsable de pagar la suma y la orden se comprometía a no arrogarse nada por dicho concepto. En otros instrumentos destinados a poblaciones, como a la Almunia de Doña Godina, los dignatarios de la orden también se comprometían a no reclamar las mencionadas rentas arbitrarias o peytas, ibidem, p. 191. En una sentencia que zanjaba las diferencias entre los habitantes de Sant Celoni y la orden en 1203 se afirmaba que dichos dependientes no estaban obligados a toltes y questies, que eran también rentas arbitrarias, Josep María Pons i Gurí, "La comanda de l'Hospital de Sant Joan de Jerusalem a Sant Celoni", Actes de les primeres jornades sobre els ordes religioso-militars als països catalans (segles XII-XIX), Tarragona, Diputació de Tarragona, 1994, pp. 288-314: p. 297.

139.- J. Alturo, Diplomatari d'Alguaire, 123 (1200); 165 (1208); J. Alturo I Perucho, Diplomatari d'Alguaire i del seu monestir duple... (1245-1300), 5, 6, 8, 10, 27, etc. En la encomienda de Barcelona se registraron varios establecimientos a censo entre 1274 y 1288, ACA, GPC, 1: 2, 3, 4, 5, $7,8,9,12,13,14,15,16,17,18,21,22,23,24$, etc. 
ción musulmana en Aragón, en Cataluña Nueva y en tierras valencianas, que además favoreció su sujeción a los señores, la especificidad de orden militar y regular del Hospital. En distintos lugares del patrimonio hospitalario hubo comunidades mudéjares, que fueron destacadas en el medio rural de la ribera del Ebro, o en los afluentes como en el valle del Jalón y del Huerva, siendo incluso la población mayoritaria en determinados enclaves como Grisén. Algunos musulmanes obtuvieron contratos de explotación semejantes a los de los cristianos, pero sus condiciones fueron en general peores y distintas, y muchos fueron sometidos al régimen de exariquia ${ }^{140}$. En 1207, Mahomet de Rex y su hijo Abceyd se "ofrecieron" como exaricos en una heredad del Hospital en presencia de los cristianos y musulmanes de Ricla, significándose públicamente su nueva situación. El documento es elocuente de la consideración diferenciada del colectivo, ya que se insiste que las prestaciones que comporta dicha condición son las que los otros musulmanes de Aragón deben al rey ${ }^{141}$. Las rentas exigidas a los musulmanes eran más onerosas que las de los pobladores cristianos, se les impedía transferir la tenencia y pagaban rentas distintas como la "alguaquela" o la "sofra" dependiendo del sitio. Las características de las órdenes militares permitían el sometimiento de la población musulmana que en ocasiones fue levantisca y sujeta a un mayor control que aquella cristiana. Algunas aljamas, como la de Silla, se levantaron en contra de sus señores hospitalarios, pero la institución tuvo mecanismos para reducir y castigar a los musulmanes. Dicha comunidad fue deportada al norte, a la Aldea - muy cerca de Amposta- y sus bienes en Silla concedidos a cristianos a mediados de siglo XIII ${ }^{142}$.

Esto se relaciona con una de las singularidades del priorato navarro, como fueron las vinculaciones agrarias con las comunidades judías, más que todo financieras ${ }^{143}$ y en último término con las mudéjares, recibidas del Temple a partir del siglo XIV. Estas últimas, numerosas sobre la cinta del Ebro, fueron especialmente activas en los trabajos agrarios, de manera que no extraña la

140.- Ma L. Ledesma Rubio, La encomienda, pp. 168-172, y Templarios, pp. 186-189.

141.- AHN, códice 650, 496, p. 511: ...facti sunt exaricos de illos pauperes Ultramare. Las exigencias reclamadas eran singulares y diferentes a las contemporáneas cristianas. Así debían satisfacer renta en especie, prestaciones en trabajo como por ejemplo transportar la simiente dos días, trillar un día, transportar madera y de ...de peita, de alart, de pechera, de jugaria. Se les impedía vender la heredad.

142.- Ambrosio Huici, María Desamparados Cabanes, Documentos de Jaime I de Aragón, IV, Zaragoza, Anubar, 1982, p. 58 y J. Mª FonT Rius, Cartas de población, 303.

143.- Tenemos constancia de estas relaciones financieras, sobre todo a partir del siglo XIV, cuando aparecen prestamistas judíos en las distintas operaciones de préstamo a la comunidad sanjuanista, dentro de su compleja trama de expansión patrimonial (AHN, Órdenes Militares, San Juan de Jerusalén, carp. 872, n. 19; carp. 884, n. 208; carp. 869, n. 17 y 18 y carp. 859, n. 3; Publican los tres últimos: Juan Carrasco, Fermín Miranda y Eloísa Ramírez Vaquero, Los judíos del reino de Navarra. Documentos 1334-1350, Pamplona, Gobierno de Navarra, 1995, n. 352, 353 y 354. 
emisión de una carta de población, por parte del prior Guido de Severach, que reorganizó la comunidad musulmana de Urzante en $1312^{144}$, y estableció las condiciones para fijar a una población que articulaba importantes espacios en el área de Cascante.

Otra de las realidades propias de la explotación y campesinado en Navarra fue la de los collazos. El clásico sistema dominial del Hospital, que principalmente se apoyó en las vinculaciones contractuales establecidas dentro de un marco señorial entre las autoridades del priorato con sus collazos ${ }^{145}$, designación genérica aplicada a campesinos ligados a la explotación de unas tierras, sufrió también variaciones y evoluciones hasta finales del siglo XV. Asimismo esos collazos presentaban una serie de características que los hacía diferentes a los clásicos siervos, ya que, según consta en los documentos, parece que su vínculo era económico más que social; y así se desprende de las listas de relación de pechas y pecheros elaboradas en las encomiendas durante el siglo XIII: Cuenca de Pamplona, el valle de Ulzama, Olaz, Arlegui, Cizur, Zariquiegui, Óriz, Leache o Zufía ${ }^{146}$. Dicha práctica de relaciones censales, cabe señalarse también, que se llevó a cabo durante dicha centuria por parte del Temple: Aberin (1263 y 1268), Garínoain, Sansomain.

Por ello, la dependencia jurídica y las contraprestaciones serviles fueron más tenues, y muchas veces sustituidas por cargas censales, caso de los labradores de Zufía (1221), Esténoz y Acella (1254), Yárnoz (1255), Gomacin (1278), Marcaláin y Garciriáin (1284), Nuin (1286) ${ }^{147}$. No obstante, ello no significa que arrastraran algunas cargas serviles, incluso durante los siglos XIV y XV, inherentes al sistema de dependencia de la época y del territorio navarro (cena, Cizur Menor, 1309). Si bien procederá analizar con mucho mayor cuidado la implicación de los términos "collazo" y "collación" a partir, aproximadamente, de 1300, pues quizá fuese asumiendo en parte una significación diferente, ganando peso la cuestión económica del arrendamiento entre personajes de condición libre, respaldados por los sanjuanistas con el objetivo de avivar o renovar las actividades agrarias sobre tierras fértiles: Cizur Menor (1309), Labiano (1318) e Imarcoian (1338) ${ }^{148}$.

144.- Lucien Barrau-Dihigo y M. Hartwig Derenbourg, "Une Charte Hispano-arabe de l'année 1312” en Revue Hispanique, 20, 1909, pp. 305-315; José ZALBA, "Documento curioso", Boletín de la Comisión de Monumentos de Navarra, 18, 1934, pp. 33-34, y Pilar Tello LÉon, "Carta de población a los moros de Urzante", $1^{\text {er }}$ Congreso de Estudios Árabes e Islámicos, Madrid, Comité Permanente del Congreso, 1964, pp. 329-343.

145.- S. García Larragueta, El gran priorado de Navarra, pp. 207-213.

146.- PSJ, n. 104-110.

147.- PSJ, n. $176,350,362,368,448,482$ y 488.

148.- AHN, Ordenes Militares, San Juan de Jerusalén, carp. 883, n. 200; carp. 936, n. 17 y carp. 885, n. 231. 


\section{La destacada proyección patrimonial en ciudades y villas}

El reino de Pamplona-Navarra estaba lejos de los grandes circuitos comerciales andalusíes, si bien fue favorecido por la vertebración de la ruta jacobea y el renacimiento urbano. Probablemente este fenómeno de crecimiento, entre otras razones, influyó para que los sanjuanistas fueran beneficiados con el palacio y la iglesia de Santa María en el burgo nuevo de Sangüesa, por parte de Alfonso I el Batallador (1129), y más tarde con los palacios reales de Estella, por iniciativa del monarca Sancho el Sabio (1165). Pocos años después recibirían una casa en Barañáin, a las afueras de los burgos pamploneses (1173), de manos del obispo. Los establecimientos, con un perfil netamente urbano del Hospital, se considerarían idóneos, no sólo para centralizar futuras redes organizativas, sino también, para impulsar su labor asistencial a lo largo de la ruta compostelana; e incluso para introducirse en los circuitos económicos de dichas ciudades.

En este sentido, la orden del Hospital logró un nivel de proyección urbana en los territorios estudiados superior y distinto al que otras órdenes regulares contemporáneas alcanzaban a desarrollar, con la salvedad de las mendicantes. Era común que las grandes comunidades cenobíticas, como las cistercienses, tuviesen su casa en las ciudades, pero los hospitalarios tuvieron encomiendas con sede urbana como la muy destacada de Zaragoza, u otras como Huesca, Lérida o Barcelona ${ }^{149}$. También obtuvieron casas y tierras en Valencia en 1238, así como propiedades en sus proximidades, Cullera, Torrent o Silla. Zaragoza fue una encomienda riquísima, con muchos ámbitos dependientes y gran cantidad de tierras. No obstante la importancia rural, cabe llamar la atención sobre la cantidad notable de casas diseminadas por varios barrios de Zaragoza, cuyos censos constituyeron la fuente primordial de ingresos de la casa central de la encomienda según sostiene M. L. Ledesma ${ }^{150}$. Tal situación expresa contundentemente la importancia de los censos urbanos para la orden, y sobre todo la variedad de recursos y procedencias que alimentaban una compleja economía. La pluralidad de espacios, de fuentes de renta y de fórmulas de explotación constituían un entramado económico que tenía en la acumulación de recursos, en principio para Ultramar y finalmente para otros quehaceres, una característica principal de su dinámica en la definición y explotación patrimonial. Dicho acervo financiero convirtió al Hospital en una institución acaudalada que podía efectuar préstamos como por ejemplo al mismo rey.

149.- J. Miret i SAns, Les cases de Templers y Hospitalers, pp. 190-191. Barcelona era una encomienda hospitalaria de menor entidad, pero con todo tuvo comendador al frente desde temprano, a mediados del siglo XII.

150.- Ma L. Ledesma Rubio, La encomienda, p. 163. 
En el caso navarro, y a pesar de que la monarquía impulsó la presencia de San Juan sobre importantes focos urbanos del Camino de Santiago, la retícula y gestión de los bailíos se basó principalmente sobre la administración del patrimonio y rentas agrarias. Además, el cuantioso mapa de encomiendas navarras se sostenía a partir de focos de habitación campesinos. De hecho, el tramo norte del priorato se vertebró sobre encomiendas establecidas a partir de villas agrícolas de tradición centenaria, caso de Cizur, Leache, o Iracheta. Y en su tramo sur, las encomiendas se asentaron sobre unas localidades agrarias, igualmente, pero con unas características un tanto distintas a las pirenaicas y prepirenaicas. De hecho, estas últimas habían heredado la fisonomía poblacional de los modelos musulmanes: núcleos de tamaño medio que aglutinaban a una activa población rural y generaban activos intercambios comerciales locales y regionales. Es el caso de Tudela, Villafranca, Calchetas o Ribaforada. De forma análoga en los territorios de la corona de Aragón, las ciudades menores o villas secundarias fueron sede o ámbito de despliegue patrimonial sanjuanista. Sirva como testimonio la presencia patrimonial o comendaticia, dependiendo a veces de la cronología, en Calatayud, Caspe, Fraga, Vilafranca del Penedès, Cervera, y en las menos destacada Sant Celoni o Ulldecona por mencionar algunas. En estas localidades como en las ciudades referidas, la orden obtuvo patrimonios urbanos y rentas de casas u otras actividades urbanas.

\section{Organización poblacional agraria: auge de poblaciones y oligarquías rurales}

Las cartas de población constituyeron el marco legal desplegado por los hospitalarios para favorecer la población de determinados núcleos de habitación rural, concentrar la población y sobre todo impulsar la explotación agraria de su término. La orden concedió cartas de población en ámbitos de las conquistas de los siglos XII y XIII en Aragón, Cataluña Nueva y Valencia. Mediante estos instrumentos los hospitalarios perseguían fijar a los pobladores, o atraer a nuevos habitantes, y legislaron sobre aspectos de la vida local, como, por ejemplo, la corrección o contención de la violencia ${ }^{151}$.

La población o ocupación era fundamental para garantizar el éxito de las conquistas, y las órdenes, en este caso el Hospital fomentaron la población. La monarquía había implicado a las órdenes en esta dirección como en la donación ad populandum de la villa de Sollavientos al Hospital efectuada por

151.- Así, por ejemplo, algunas normas destinadas a contener las acciones violentas junto a otras disposiciones legales en las cartas de población de Cetina o la de Aliaga, M. L. Ledesma Rubio, Cartas, 80 (años 50 del siglo XII) y 162 (1216). 
Pedro II en 1205 para favorecer la ocupación cristina conforme a las consignas de la institución ${ }^{152}$. La urgencia de poblar determinados distritos hospitalarios motivó la concesión de distintas cartas como las otorgadas en localidades del Maestrazgo de Castellón ${ }^{153}$. La carta de población de Cervera de 1235 estaba destinada a promover la ocupación cristiana al haberse desplazado a los musulmanes fuera de la localidad. Además en esta y otras de la región, se fomentaron las contribuciones militares de los moradores y fueron objeto de exigencia tributaria relacionada con expediciones, como el quinto que se arrogaban los hospitalarios en los botines, captura de hombres y ganado efectuados por los pobladores de estas localidades ${ }^{154}$. Eran encomiendas de frontera o de tierras recién conquistadas, y dicha condición implicaba a los pobladores del dominio en las actividades específicas del emplazamiento. Sin embargo, la orden reclamaba este tipo de prestaciones en otros ámbitos de su jurisdicción que no eran fronterizos, como en la encomienda de Sant Celoni, no sin resistencia de sus habitantes. No querían participar en una hueste que sus señores, los hospitalarios, habían organizado para luchar en Hispania, aunque una sentencia de 1203 validó los derechos de la orden en su derecho de hueste ${ }^{155}$.

El proceso de concesión de cartas de población fomentó o consolidó la existencia de oligarquías rurales que fueron agentes del gobierno comendatario, como los repartidores o divisores, quienes dividían las parcelas de cultivo entre los agricultores dependientes como se ordenaba en las cartas de población del Montsià o en la de Cervera ${ }^{156}$. Los beneficiarios de las cartas eran personas destacadas de la localidad o región y los cultivadores, a quienes se les exigía que fijasen residencia en casos como en la Font de la

152.- Ma L. Ledesma Rubio, Cartas, 148 (1205): ad populandum et tenendam et custodiendum ad honorem Dei et fidei Christiane....

153.- Por ejemplo las cartas de población de Càlig (1234), Cervera (1235) y el Rossell (1237), E. DíAZ Manteca, El «Libro de Poblaciones», Castelló, Diputació de Castelló, 1987, pp. 183-185, pp. 181182 y pp. $186-187$.

154.- La retención del quinto del botín para la orden se precisó en las cartas de población de Càlig, Cervera el Rossell y la anterior de Aliaga ya referidas. En las cartas de población de las localidades del Maestrazgo, Càlig (1234), Cervera (1235), en el sur de Cataluña, la Sénia (1236) y la localidad cercana de Rosell (1237), los pobladores quedaban comprometidos a hacer prestaciones militares en los llamamientos efectuados por el rey, justo en plena conquista valenciana, J. M ${ }^{\mathrm{a}}$ FonT RIUS, Cartas de población, 265. En la carta de población de Torrente de Cinca, se exigía a los habitantes su prestación de "hacer ejército real", Mª L. Ledesma Rubio, Cartas, 171 (1230). Más adelante se pedían sólo huestes y cabalgadas en otro instrumento poblacional destinado a los pobladores de Cervera, en este caso en el contexto posterior a la conquista, ibidem, pp. 182-183 (1249).

155.- J. M. Pons I GuRí, "La comanda", p. 297.

156.- Ma Bonet, "Las cartas de población y el dominio hospitalario del Montsià (siglo XIII)", Miscel-lània en homenatge al P. Agustí Altisent, Tarragona, Diputació de Tarragona, 1991, p. 551-571 y E. DíAZ Manteca, El «Libro de Poblaciones, pp. 181-3. 
Ametlla o Alcanar, garantizándose así la explotación agraria y en definitiva las rentas. Los hospitalarios requerían prestaciones agrarias en los documentos poblacionales como diezmos, primicias, la tasca y otros censos agrarios, o rentas jurisdiccionales como las militares referidas ${ }^{157}$. Tales exigencias eran sólo parte del conjunto abigarrado de obligaciones censitarias y jurisdiccionales a las que estaban sometidos los labradores del patrimonio hospitalario y dependientes del poder comendaticio.

La lejanía de la frontera musulmana, así como la ausencia de espacios navarros por reorganizar ya en el siglo XII, motivó que los sanjuanistas tuvieran un papel protagonista en un proyecto que no existió para este priorato, pero sí para el resto de prioratos hispanos, como en el de la castellanía de Amposta, esto es la reconquista y la repoblación. De manera que al margen del señorío sobre casi una veintena de villas, dos de ellas de origen templario, el prior no tuvo la actividad de implicaciones poblacionales de otros ámbitos peninsulares. De manera que sus relaciones con los núcleos de población se encuadran, más bien, en otro ámbito; esto es el de los conflictos por las rentas señoriales (1387, Oteiza; 1432, Ribaforada), e incluso eclesiásticas, y las prestaciones complementarias (1330, Aberin).

\section{A MODO DE CONCLUSIÓN}

La aparición, implantación y desarrollo de la orden de San Juan de Jerusalén en el tramo oriental del tercio peninsular - la unidad geomorfológica del valle del Ebro con sus márgenes montañosos pirenaico, ibérico y la banda costera mediterránea- diversificó y enriqueció los horizontes y contornos socioeconómicos de las tierras bajo el dominio de la soberanía aragonesa y pamplonesa. La irrupción de una nueva institución con carácter religioso pero claramente diferenciada del sistema monástico—, tutelada por el Papado y con perfil internacional inscribió un sistema organizativo inicialmente extraño a los modelos existentes a comienzos del siglo XII. Esta formación patrimonial y el desarrollo institucional del Hospital en el tercio nororiental hispano fueron singulares en el conjunto de la renovación de los regulares de dicha época. La funcionalidad, si se quiere las funcionalidades, militar,

157.- Algunas exigencias tenían como destinatario a los pobladores como los ochenta cahices de cereales anuales exigidos a los treinta y siete pobladores de Candasnos por la priora de Sigena, M. L. Ledesma Rubio, Cartas, 163 (1217). En algún caso, como en la Almunia de doña Godina en 1247, un segundo instrumento poblacional detallaba el censo agrario, en este caso una arroba de trigo y otra de cebada por cahizada de tierra, puesto que en la primera carta de 1178 no expresaba su valor en función de la tierra, ibidem, 191 y 113. 
asistencial, la rama femenina, y las condiciones administrativas de la orden favorecieron su desarrollo en el marco de las nuevas realidades sociales y políticas. El patrimonio sanjuanista abrazó todo tipo de ámbitos territoriales y significativamente los estratégicos, ya fuese en lo económico o en lo políticomilitar. En ese sentido, los enclaves hospitalarios salpicaron las variadas geografías de los territorios aragoneses, catalanes o navarros. Las propiedades y sus desarrollos comendaticios se ubicaron en tierras del Pirineo, en cuencas fluviales feraces, en ciudades, en localidades secundarias y en la frontera, no sólo frente a los musulmanes, sino entre Navarra y Aragón.

La monarquía o los condes, inicialmente, tuvieron un papel preponderante en su asentamiento, al igual que en Castilla, procurando la protección y ampliación de su patrimonio y creando un modelo de conducta seguido por la nobleza, influida asimismo por los patrones de la nueva espiritualidad y en última instancia por el interés de participar en los flujos económicos de protección y ayuda a los freires que custodiaban y protegían los Santos Lugares. No obstante, la vestimenta de institución supranacional centralizada en los asuntos del Oriente Latino, cubría un cuerpo en Occidente con miembros regidos por unos mismos principios, pero con rasgos distintivos. De ahí que la organización interna de los prioratos analizados tenga, al igual que en otras de las circunscripciones algunas particularidades, reflejando, a fin de cuentas las trayectorias y modelos de funcionamiento regionales en una demarcación como sujeto y a la vez objeto de una gestión interna y externa.

La territorialización patrimonial de los sanjuanistas fue, en gran medida y por tanto, resultado del patrocinio regio y de un programa impulsado por la monarquía. Para las principales figuras políticas de estos reinos y territorios, el Hospital y también el Temple, sirvieron a varios propósitos de proyección y dominación de regiones sobre las que pretendían o empezaban a ejercer algún tipo de autoridad, para el caso de las empresas aragonesas. En ese sentido, las demarcaciones priorales fueron de cuño político en su gestación y consolidación, aunque tales formaciones no impidieron que los respectivos líderes políticos mantuvieran el reconocimiento y vínculos con los poderes suprarregionales ligados a la centralidad institucional.

La institución formaba parte de una estructura internacional unitaria que le procuró un tipo de administración centralizada, colegiada y dinámica. Estas características proporcionaron a su vez un modelo de organización comendaticia que era versátil y adaptable a las necesidades. En ese sentido, en determinados ámbitos como algunos de los recién conquistados, las encomiendas se formaron muy rápidamente, mientras que en otros la autoridad comendaticia estuvo diluida y a veces asociada a una preceptoría mayor. Algunas encomiendas fueron minúsculas, otras abrazaron importantes patrimonios y tales 
dimensiones o desarrollos eran el reflejo de un patrimonio variado y adaptado o diseminado en ámbitos bien distintos. La teórica obtención de un hombre de cada religión en distintas villas aragonesas que se había reservado el maestre del Hospital era premonitoria de una patrimonialización que sería una territorialización de células de cierto interés estratégico, económico, social o militar.

Navarra presentó un modelo de formación patrimonial mediatizado por las circunstancias políticas del alzamiento de García Ramírez, al margen de las disposiciones del Batallador y de los acuerdos posteriores suscritos en Aragón. No obstante, no sólo fueron los entornos diplomáticos de la presión castellano-aragonesa, que dejaron a Navarra sin un frente activo o frontera ante el Islam y quebrando a la vez unos más que deseables horizontes de ensanchamiento social. Sino que también la recepción de la institución se hizo sobre un territorio caracterizado por una economía rural, local y de propiedad fragmentaria. De hecho así se refleja en las compras y donaciones de las elites locales y de la nobleza que se documentan desde la década de los sesenta y setenta del siglo XII. La nota dominante de la articulación del sistema comendaticio dibujó, por tanto, esa realidad, sin que por ello repercutiera negativamente en el desarrollo y funcionamiento del Hospital. Llama la atención, empero, las acciones por rehabilitar o revitalizar las explotaciones, en actuaciones cuyo objeto fue rentabilizar algunas explotaciones de escaso rendimiento, ampliar los lotes de tierras con otras posesiones, fincas, granjas o dominios complementarios, como al mediodía de la cuenca de Pamplona o en las riberas del Ebro (Calchetas, Cabanillas y Fustiñana). De manera que las actividades, que soportaban la población pechera — campesinos, pecheros o exaricos-, tuvieron como denominador la constante mejora y racionalización de unas rentas que, aunque dispersas en género y geografía, confluían hacia un mismo punto organizativo.

En los ámbitos de la unión de Aragón y Cataluña, el testamento concitó una serie de beneficios territoriales en tierras conquistadas y sobre todo significó la vinculación e instrumentalización del instituto por parte del conde y luego la monarquía. Los embriones de encomiendas, y sobre todo su funcionalidad radicaban en las necesidades de dominación sobre tierras y poblaciones, ya fuese en la frontera o en el valle del Ebro, que el Hospital podía resolver con ciertas garantías por sus características. Así algunas preceptorías formaron parte de la ocupación de espacios fronterizos, otros recién conquistados y en algunos con población campesina musulmana sometida. Además otros emplazamientos en ciudades o villas ofrecieron una articulación territorial novedosa en la medida que territorializaba una variedad significativa de sitios, y en forma bien distinta a la conocida para un monasterio con un centro con subámbitos de dominación. La patrimonialización del Hospital se acompañó 
de fórmulas de compensación para aquellos sujetos afectados por el proceso, quedando temporalmente vinculados a la institución o a su patrimonio dependiendo de los casos. La explotación de dicho patrimonio revistió fórmulas distintas en las modalidades de censos y cartas de población, creando lazos y obligaciones diversas como la emergencia de oligarquías rurales o las exigencias militares, significativamente en determinados ámbitos.

Los variados procesos referidos culminaron en la existencia de una institución de corte eclesiástico en su concepción y al servicio de las nuevas realidades políticas, territoriales y por supuesto sociales. Así la importante patrimonialización se fue acercando a una destacada territorialización con espacios y una pluralidad de núcleos centrales que configuraban una complejísima y amplia retícula para la provisión de recursos y la dominación territorial. 
MARÍA BONET DONATO Y JULIA PAVÓN BENITO

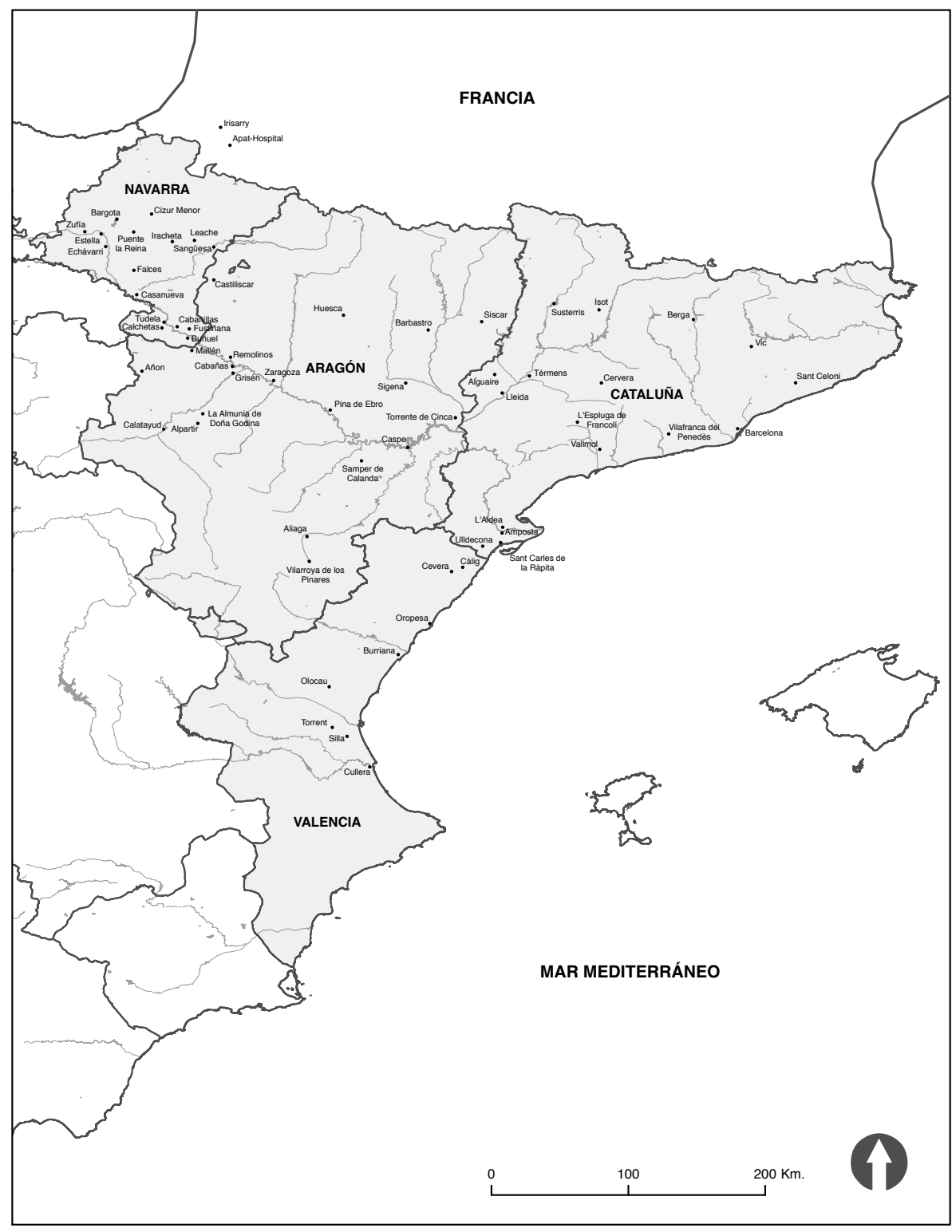

